\title{
ANUARIO LOpe
}

\section{LA TRADICIÓN MANUSCRITA E IMPRESA \\ DE EL MEJOR ALCALDE, EL REY, DESDE FINALES \\ DEL SIGLO XVII HASTA FINALES DEL SIGLO XVIII}

\section{Fausta Antonucci (Università Roma Tre)}

Cita RECOMENDADA: Fausta Antonucci, «La tradición manuscrita e impresa de El mejor alcalde, el rey, desde finales del siglo XviI hasta finales del siglo xviI», Anuario Lope de Vega. Texto, literatura, cultura, XXVIII (2022), pp. 262-298.

DOI: <https://doi.org/10.5565/rev/anuariolopedevega.446>

Fecha de recepción: 19 de julio de 2021 / Fecha de aceptación: 18 de agosto de 2021

\section{Resumen}

Se examinan tres manuscritos tardíos de El mejor alcalde, el rey nunca cotejados para las ediciones modernas del drama de Lope: el que se conserva en la Biblioteca de la Hispanic Society of America y dos que atesora la Biblioteca Histórica Municipal de Madrid y que proceden de los archivos de los teatros de la Cruz y del Príncipe. Ninguno de estos testimonios parece derivar de una rama de la tradición textual más cercana que el texto de la Parte XXI al perdido original de Lope. Aun así, su estudio detenido nos revela aspectos interesantes de la transmisión de textos en el mundo del teatro, permitiendo, entre otras cosas, esclarecer la historia de la fortuna de este drama de Lope en los tablados madrileños entre finales del siglo xviı y finales del siglo xviII.

Palabras Clave: Lope de Vega; manuscritos teatrales; transmisión textual; apuntes de teatro.

Abstract: The Handwritten and Printed Tradition of El mejor alcalde, el rey, From the End of the $17^{\text {th }}$ Century to the End of the $18^{\text {th }}$ Century.

Three late manuscripts of El mejor alcalde, el rey never collated for modern editions of Lope's drama are examined here: the one that is preserved in the Library of the Hispanic Society of America and two that are housed in the Biblioteca Histórica Municipal of Madrid and that come from the archives of the corrales Cruz and Príncipe. None of these testimonies seems to derive from a branch of the textual tradition closer than the text of the Parte XXI to the lost original of Lope. Even so, its careful study reveals interesting aspects of the transmission of texts in the world of theater, allowing, among other things, to clarify the history of the fortune of this drama by Lope in Madrid's tablados between the end of the $17^{\text {th }}$ century and the end of the $18^{\text {th }}$ century.

KeYwords: Lope de Vega; Theatrical manuscripts; Textual transmission; Apuntes de teatro. 
1. $\begin{aligned} & \text { unque pueda parecer paradójico en una obra tantas veces editada moderna- } \\ & \text { mente como es El mejor alcalde, el rey de Lope de Vega, ninguno de los estu- }\end{aligned}$ diosos que hasta la fecha se ha dedicado a editarla se ha preocupado por escudriñar a fondo la historia de su transmisión textual. Para restituir la lectura correcta en caso de errores de la princeps (el texto incluido en la Parte XXI de comedias de Lope de Vega), los editores modernos suelen acudir a la suelta impresa en Madrid por Antonio Sanz en 1741 o a enmiendas ope ingenii que, como en el caso de la edición de Hartzenbusch de 1853, son muchas veces innecesarias o discutibles. Nadie ha cotejado nunca el manuscrito conservado en la Biblioteca de la Hispanic Society of America, fechado por Regueiro y Reichenberger [1984:470-472] entre el siglo xvII y el siglo xVIII; ni las demás sueltas de la segunda mitad del siglo XvIII; ni los dos manuscritos conservados en el rico fondo teatral de la Biblioteca Histórica Municipal de Madrid, junto con tres apuntes impresos que utilizan dos de las sueltas ya mencionadas. ${ }^{1}$

Digamos desde ya que ninguno de estos testimonios, por sus características textuales y su posición en el stemma, es capaz de disputar al texto de la Parte su autoridad, ni muestra indicios de derivar de una rama diferente de la tradición textual, más cercana que el texto de la Parte (que llamaremos $A$ ) al perdido original de Lope. Aun así, su estudio detenido nos revela aspectos interesantes de la transmisión de textos en el mundo del teatro, permitiendo, entre otras cosas, esclarecer la historia de la fortuna teatral de este drama de Lope entre finales del siglo xviI y finales del siglo xviII, y resolver las dudas que los estudiosos se han planteado acerca de si las representaciones de El mejor alcalde, el rey consignadas en documentos de finales del siglo xvi y de todo el siglo siguiente eran de la obra de Lope o de la refundición homónima de Martínez de Meneses. ${ }^{2}$

1. He podido consultar estos textos, para preparar la edición crítica de El mejor alcalde, el rey, gracias a la ayuda imprescindible de Laura Fernández, de Ramón Valdés y del grupo PROLOPE, con sus recursos y su buen hacer. Dicha edición crítica se enmarca en el proyecto de edición de la Parte $X X I$ de las comedias de Lope que coordinan Gonzalo Pontón y Ramón Valdés, a los que agradezco su constante ayuda y su disponibilidad a discutir conmigo muchas de las cuestiones ecdóticas que abordo en estas páginas.

2. Dudas que manifiestan Andioc y Coulon [1996:775, 911], por ejemplo, siguiendo a Varey y Davis. El título completo de la refundición de Antonio Martínez de Meneses es El mejor alcalde el rey, y no hay cuenta con serranos, publicada en la Parte veinte de comedias varias nunca impresas, 
La primera etapa de nuestro recorrido se centrará en la descripción de las características materiales de los tres manuscritos ya mencionados, empezando por el más antiguo de los dos que se conservan en la Biblioteca Histórica Municipal de Madrid: el que se identifica con la signatura Tea 1-49-6,B de acuerdo con los criterios de catalogación de apuntes de teatro que describe Ascensión Aguerri [2007:147-149]. Este manuscrito, al que en mi edición crítica de El mejor alcalde, el rey atribuyo la sigla $M a$, pertenece al rico fondo procedente de los archivos de los teatros madrileños de la Cruz y del Príncipe. Prácticamente desconocido para todos los catálogos del teatro de Lope (Pérez y Pérez 1973, y el apartado bibliográfico de la ficha correspondiente a El mejor alcalde, el rey de ARTELOPE), el catálogo en línea de la Biblioteca Histórica Municipal de Madrid lo fecha de forma conjetural en 1710, debido a que se halla envuelto en una carta fechada en Segovia el 20 de diciembre de este año.

El texto de la carta, firmado por José Antonio Guerrero, ocupa el recto y el vuelto del último folio del manuscrito y reza así: ${ }^{3}$

Amigo y señor mío:

Bien sabe V.M. que no he faltado a servirle en aquel poco posible que los tiempos me tienen y que le aguardábamos toda la comp[añí]a; y en cuanto a la queja de los dos Antonios respondo que no harán más de lo que yo dijere, que la comp[añí]a lo que dice es que quieren que V.M. salga siempre al tablado y que se le dará su partido ingeniándose para vestirse ya con los compañeros o ya con los del lugar. En esta conformidad puede V.M. venirse luego con la mujer de Capa si ya no es que tenga mayor conveniencia, que en tal caso no quiero más del que fuere del agrado de V.M, a quien suplico se entere bien del quinto de Molina y que espesifique con la jardinera el trato que tiene hecho con él por escrito y que yo no conosco censo ninguno en el jardín como lo dirán los papeles míos; y vea V.M. quién son los inquilinos que tiene la casa, tome sus nombres y la razón de lo q[ue] deben y si vive en la casa ant[oni]o [...] el que vende chocolate le dé muchos [re]cados míos y que tome por su cuenta el cuidar de la vecindad de

compuestas por los mejores ingenios de España (Imprenta Real, Madrid, a costa de Francisco Serrano de Figueroa, 1663, pp. 328-363).

3. En realidad no es el último folio del manuscrito, sino lo que en un libro llamaríamos contracubierta, pues la carta, formada por sobreescrito y carta propiamente dicha, se utilizó para encuadernar el manuscrito en un segundo momento. Modernizo la grafía, manteniendo rasgos con valor fonético como el seseo; resuelvo las abreviaciones; puntúo con parquedad un texto que en el original está falto de cualquier signo de puntuación y parece reproducir con su insistente polisíndeton la estructura de una producción oral. 
la casa en tanto que yo voy a Madrid. Espero a V.M. cuanto antes y la mujer de Capa cuya vida g[uar]de Dios muchos años. Segovia y diciembre 20 de 1710. Amigo y servidor de V.M. José Ant[oni]o Guerrero. [A] Ju[an] de la Calle.

El sobrescrito, que se encuentra en el folio que precede a la portada del manuscrito, reza: «A Juan de la Calle g[uar]de Dios muchos años, representante en Madrid». Otra mano escribió en el margen superior de esta hoja los elementos de attrezzo necesarios para la puesta en escena («una torre, una reja, recado de escribir, mesa y sobremesa y cinco sillas = un venablo=»), abajo la indicación «a Antonio de Capa», y en la parte inferior izquierda una lista de papeles con esa enigmática equivalencia numérica que Ruano [1982:12], en relación con una lista análoga que aparece al final del manuscrito de Cada uno para sí, supuso que fuese «probably a book-keeping account of the monies paid to the actors» [fig. 1]. ${ }^{4}$ Los nombres del remitente, del destinatario y el de Antonio de Capa que se menciona también en la carta, apuntan todos al mundo teatral de finales del siglo XVII y comienzos del xVIII: José Antonio Guerrero era un autor de comedias cuya actividad teatral según el DICAT empieza a estar documentada con certeza en 1670, y que efectivamente en 1710, según Grau [1958:43], representó en Segovia; Juan de la Calle, actor y apuntador, era hermano de Salvador de la Calle que ya trabajaba como actor en la compañía de Guerrero desde 1691; mientras de quien menos noticias tenemos es de Antonio de Capa (o Antonio Capa en el DICAT) de quien solo se atestigua la actividad como actor y apuntador entre 1701 y 1705 . El hecho de que la carta, fechada en 1710, contenga indicaciones típicas de los apuntes de teatro sobre los elementos de attrezzo y los papeles, nos dice que el texto encuadernado en dicha carta fue representado, en Madrid, por una compañía de la que formaban parte Juan de la Calle y Antonio de Capa, después de la fecha de la carta misma. ${ }^{5}$

4. Esta explicación no acaba de convencerme: si se tratara de un memorando de pagos, ¿cómo se justifica la reducida cantidad indicada y la falta de algunos papeles principalísimos, en nuestro caso el de Sancho y el de Nuño?

5. Sería, de acuerdo con las noticias que proporcionan Andioc y Coulon [1996], la compañía de José Garcés, que representó El mejor alcalde, el rey en el teatro del Príncipe en los años 1709 y 1711, y en el teatro de la Cruz en los años 1713 y 1715 . En estos casos, creo que puede afirmarse con razonable seguridad que se trataba de la pieza de Lope de Vega. A partir de 1716 —según informa el mismo repertorio de Andioc y Coulon [1996] — representan una obra con el mismo título, no sabemos si de Lope o de Martínez de Meneses, las compañías de Juan Álvarez (1716, 1721), de Sabina Pascual (1719), de Ignacio Zerquera (1722, 1723, 1724, 1735, 1737), de Londoño (1725), de Antonio Vela (1727) y de Juana de Orozco $(1729,1730,1731,1732,1733,1734,1738)$. Los teatros de la Cruz y del 
Pero este texto no fue copiado para esa ocasión, sino en fecha bastante anterior. Buscando en el rico repertorio de la base de datos Manos, di con un manuscrito que de forma inequívoca puede adscribirse al mismo copista: el de El español más amante y desdichado Macías, de Francisco Bances Candamo (BNE Ms. 16.670). A partir de ahí, tirando del hilo de este copista desconocido, al que Manos atribuye la sigla P970, y con la ayuda fundamental de Alejandro García Reidy, comprobé que el mismo amanuense copió otras obras de Bances Candamo: El duelo contra su dama (BNE Ms. 16.010); El Austria en Jerusalén (BNE Ms. 14.832); la Mojiganga para el auto sacramental del Primer duelo del mundo (BNE Ms. 17.313). Este auto sacramental, según informa el DICAT, fue representado en Madrid en 1687 por la compañía de Agustín Manuel de Castilla; la misma compañía representó en $1691 \mathrm{El}$ duelo contra su dama, en el Alcázar de Madrid, para celebrar el cumpleaños de la archiduquesa María Antonia. No sería extraño, pues, que P970 fuese en estos años el apuntador de la compañía de Agustín Manuel, y que copiara el manuscrito de El mejor alcalde, el rey que nos ocupa para la particular que la misma compañía representó el 23 de abril de 1692 en el Real Alcázar (Shergold-Varey 1979:292). Si así fue, y todo parece indicarlo, la que se representó fue la obra de Lope y no la homónima de Martínez de Meneses, lo que permitiría despejar las dudas de los estudiosos al respecto y fechar nuestro manuscrito en 1692.

En los años durante los cuales Ma corrió por los tablados (desde 1692, si mi conjetura es cierta, hasta al menos 1710), el manuscrito, inicialmente una copia en limpio muy pulcra y cuidada, cobró el aspecto típico del apunte de teatro, con tachaduras, atajos, correcciones e innovaciones de todo tipo, realizadas por al menos dos manos: una, a la que he llamado $M a^{1}$, que escribe con letra basta y con tinta a veces más clara, a veces más oscura (por lo que podría no tratarse de una sola mano); otra, a la que he llamado $M a^{2}$, que escribe con letra más elegante. Esta segunda mano subsana dos de las lagunas de texto que $M a$ hereda de $A$, la falta de los vv. 684 y 1292 [fig. 2]; a $M a^{1}$, en cambio, parece que deben adjudicarse otras correcciones menores.

$\mathrm{Al}$ contrario de $M a$ (entendiendo con esta sigla el manuscrito en su conjunto, con las intervenciones sucesivas de $M a^{1}$ y $M a^{2}$ ), el manuscrito conservado en la bi-

Príncipe estuvieron cerrados por reformas entre 1737 y 1743 (el de la Cruz) y entre 1744 y 1745 (el del Príncipe). No me parece procedente seguir listando las compañías que representaron una obra del mismo título después de estas fechas, ya que nos vamos alejando muchísimo de la fecha probable en la que el manuscrito $M a$ se encuadernó en la carta mencionada de 1710. 
blioteca de la Hispanic Society of America (signatura B2640), que llamo $M b$, es una copia en limpio sin prácticamente tachaduras ni intervenciones. Su paginación, antigua, empieza con el número 611 ; lo que leemos en esta página es el texto de $E l$ mejor alcalde, el rey a partir del v. 37. Le falta por tanto al manuscrito un folio entero, en cuyo recto (la que sería la página 609) se escribirían el título, la lista de dramatis personae, la acotación inicial y los primeros versos, mientras que el vuelto (la que sería la página 610) contendría la continuación del monólogo inicial de Sancho hasta llegar al v. 36. Por la paginación y por la falta del primer folio, Regueiro y Reichenberger [1984:470-472] suponen que debió de formar parte de un volumen más extenso del que fue arrancado. A diferencia de $M a$, cada acto está copiado en un cuadernillo diferente; es una práctica bastante común en los manuscritos de procedencia teatral y, de hecho, se observa por ejemplo en el de La dama duende (BNE Ms. 16.622) cuyos actos segundo y tercero fueron copiados en 1689 por Miguel de Escamilla, nieto del famoso autor Antonio de Escamilla y, al parecer, apuntador de su compañía. La forma de empezar las jornadas, así como el pequeño nudo que encabeza cada acto, se parecen bastante en ambos manuscritos, aunque en $M b$ falta la invocación devota «Jesús María Joseph» [fig. 3]. Es cierto que la escritura de Escamilla en el manuscrito 16.622 de La dama duende es bastante distinta con respecto a la de $M b$, con un ductus más rápido, las letras más inclinadas a la derecha; pero si vamos mirando en Manos otros manuscritos copiados por el mismo amanuense, observaremos que la parte que se adscribe a Escamilla en el de Bien vengas, mal, si vienes solo (BNE Ms. 15.633) se parece bastante a nuestro $M b$ [fig. 4], aunque no dejan de observarse diferencias que no nos permiten una identificación segura. ${ }^{6}$ En todo caso, creo que por su grafía este manuscrito puede fecharse con seguridad hacia finales del siglo xvII o, como más tarde, en los primeros años del siglo xviII.

Mucho más tardío es el segundo de los manuscritos de El mejor alcalde, el rey que se conservan en la Biblioteca Histórica Municipal de Madrid (signatura Tea 1-49-6,A), que llamo $M c$. La ficha catalográfica lo fecha a partir de las iniciales «FR» que figuran en la portada de los tres actos, y que el catálogo identifica con las del actor y dramaturgo Fermín del Rey, activo en la segunda mitad del siglo xviI y que hacia finales de la centuria fue apuntador de la compañía de Manuel Martínez (Doménech Rico

6. De hecho, Alejandro García Reidy, al que una vez más he sometido la cuestión, tiende a descartar la identificación del copista de Bien vengas mal con Miguel de Escamilla, y tampoco está seguro de que se trate del mismo amanuense que copió el manuscrito $M b$. 
2014:39-40). ${ }^{7}$ Cada acto se copia en un cuadernillo distinto, y en la portada de cada acto, además de las ya mencionadas iniciales «FR», se escribe la indicación «Ap.to $1^{\circ} »$ : se trata, pues, del apunte que, como recuerda Aguerri [2007:143], servía para dirigir los ensayos de los actores. Su aspecto, sin embargo, no coincide con el de los apuntes primeros de dramas románticos estudiados por Ribao Pereira [1999] que refiere Aguerri: aunque es verdad que «está escrito por una sola mano, y parece una copia en limpio de la obra», sí presenta muchas tachaduras, innovaciones y enmiendas, aunque realizadas casi todas por una mano diferente con respecto a la que copió todo el texto. Esta mano, que llamo $M c^{1}$, escribe al vuelto de la portada del segundo acto una lista de los decorados necesarios para los diferentes cuadros (informaciones que, en el estudio mencionado de Ribao Pereira, son características del segundo apunte). Se trata de escenografías fijas como las que se usaban en las postrimerías del siglo XVIII («salón corto», «salón largo», «casa pobre»...), ${ }^{8}$ que figuran asimismo en las acotaciones de las sueltas de la segunda mitad del siglo, y que, como digo, son un añadido posterior al momento de la copia de $M c$ (cuyo antígrafo carecía seguramente de este tipo de indicaciones). En otros lugares del manuscrito se añaden más indicaciones que remiten tanto a los decorados como a los efectos de luz, algunas de ellas muy detalladas [fig. 5]. $\mathrm{Al}$ vuelto de la portada del acto primero una mano diferente, que no vuelve a aparecer en el manuscrito, escribe algunos nombres de actores al lado del reparto de personajes [fig. 6]. Se descifran los apellidos Pinto, Ponce, Contador, mientras que las damas solo se indican como $1^{\mathrm{a}}, 2^{\mathrm{a}}, 3^{\mathrm{a}}$ y $4^{\mathrm{a}}$, y al lado del papel de Nuño se escribe $\mathrm{B}^{\mathrm{a}}$. Una segunda mano, que llamaremos $M c^{2}$, añade el apellido «Ynfante» al lado del papel de Sancho. $M c^{2}$ escribe también otro reparto, el que figura al vuelto de la tercera jornada [fig. 7] y en el que solo algunos papeles se completan con el nombre de actor o actriz: González hará don Tello; la Sra. Prado, Elvira; la Sra. Ríos, Leonor; la Sra. Luna, Feliciana; la

7. Su traducción de La serva amorosa de Goldoni (La buena criada) se publicó en 1778 y nuevamente en 1792 «corregida y enmendada por él mismo para la compañía de Manuel Martínez», que la representó también en 1793 y 1795. Fermín del Rey figura como apuntador primero de dicha compañía en la temporada 1792-1793 (Cotarelo y Mori 1902:530) pero, como veremos al hablar de los apuntes impresos de $E l$ mejor alcalde, el rey, es probable que siguiera trabajando para el yerno de Martínez, Francisco Ramos, que se hizo cargo de la dirección a la muerte de su suegro en 1795.

8. Son los «juegos de decorados que se utilizaban en varias obras y que formaban parte casi de los fondos fijos de los teatros» (Rubio Jiménez 2003:1831-1832). El trabajo de Rubio Jiménez versa sobre teatro del siglo xix; pero las indicaciones escenográficas que menciona («calle larga», «calle corta») se ajustan completamente a las que encontramos en $M c$ y en las acotaciones de las sueltas posteriores a 1750 . 
Sra. Torre, Juana; se confirma que Ynfante hará el papel de Sancho, Celio lo hará López, Julio lo hará Suárez, y Pelayo lo hará Cubas. Ya que el único nombre que coincide con la lista de la primera jornada es el de Ynfante, añadido allí por $M c^{2}$, pienso que $M c^{2}$ decidió copiar un nuevo reparto actualizado en el vuelto de la tercera jornada, sin seguir corrigiendo la lista inicial, que debe por tanto ser anterior a esta segunda. En ambos repartos figuran nombres de actores y actrices que, como el apuntador y copista de $M c$ Fermín del Rey, pertenecían a la compañía de Manuel Martínez; ${ }^{9}$ compañía que, de acuerdo con las informaciones que proporcionan Andioc y Coulon [1996], representó El mejor alcalde, el rey todos los años desde 1786 hasta 1791, y luego también todos los años entre 1793 y 1795. Tras la muerte de Manuel Martínez el 4 de julio de 1795, la obra siguió representándose en 1796, 1797, 1799, por la que puede suponerse que fuese la misma compañía, solo que dirigida ahora por el yerno de Martínez, Francisco Ramos. Para las representaciones de 1800, 1803, 1804, 1805, 1807, en el repertorio de Andioc y Coulon [1996] no figura el nombre de la compañía, pero veremos al estudiar los apuntes impresos que seguramente se tratara de la misma. Los datos recabados - aunque no nos permiten fechar con seguridad el año en que fue copiado $M c$ ni cuándo fue revisado y corregido por $M c^{1}$ — sí nos permiten afirmar que las representaciones de $E l$ mejor alcalde, el rey cuya noticia se consigna en los años desde 1786 en adelante debieron ser de la obra de Lope, y no de la de Martínez de Meneses. ${ }^{10}$

2. Más allá de estos datos externos, ¿qué relación textual es la que une $M a, M b$ y $M c$ entre sí y con el texto de El mejor alcalde, el rey de la Parte XXI (A)? El texto de $M a$, anteriormente a las intervenciones de $M a^{1}$ y $M a^{2}$, nos muestra una relación estrechísima con $A$, ya que comparte 24 errores de los 29 que presenta el texto de la

9. Antonia de Prado (1765-1830), esposa de Isidoro Máiquez, en la temporada 1792-1793 era tercera dama de la compañía de Martínez, y Josefa Luna, hermana de la más famosa Rita Luna, segunda dama (Cotarelo y Mori 1902:530). Pedro y Félix Cubas también figuran en un reparto de la misma compañía del año 1795, según refiere Sánchez Estevan [1915:250]. Pinto podría ser Antonio Pinto, «supernumerario de barbas en la compañía de Martínez, en 1794» (Sánchez Estevan 1915:249250), amigo de Moratín y de Dionisio Solís. López podría ser Francisco López, sobresaliente de gracioso en la misma compañía en 1792-1793 (Cotarelo y Mori 1902:530). El misterioso « $\mathrm{B}^{\mathrm{a}}{ }_{»}$ al lado del personaje de Nuño podría ser Antonio Baca, del que sabemos que en 1799 formaba parte del elenco de la compañía de Francisco Ramos, yerno de Manuel Martínez, que heredó la dirección de su compañía a la muerte de este en 1795 (Soria Tomás 2020:583).

10. También lo confirman, para el periodo 1785-1819, los datos aportados por Coe [1935:149150], procedentes del vaciado de los anuncios teatrales de periódicos madrileños de esa época. 
Parte. De los cinco errores de $A$ que no comparte, y que listamos a continuación, ninguno es separativo:

\begin{tabular}{lll} 
& A & $M a$ \\
\hline 319 & con amor & Canamor \\
$373 P e r$ & Pel. & Fel. \\
770 & quando & quedo \\
991Per & Pel. & Fel. \\
1553 & escritura & escrita
\end{tabular}

Pudieron haber sido corregidos ope ingenii por el amanuense de $M a$, si este copiaba directamente del texto impreso de la Parte; pero el estado inicial de copia en limpio de $M a$ nos inclina a suponer más bien que debió copiar de un antígrafo manuscrito muy relacionado con $A$ pero sin estos cinco errores, o por haber sido corregidos allí ope ingenii, o por encontrarse estos errores solo en $A$, debido a malas lecturas del original de imprenta por el componedor de la Parte XXI (de hecho, son todos errores paleográficos).

De los 24 errores que $M a$ comparte con $A$, al menos tres - las lagunas correspondientes a los vv. 684, 967, 1292- son plenamente conjuntivos, pues es muy difícil que hayan podido producirse de forma independiente (no los propicia ninguna característica del texto, como podría ser un salto de igual a igual). Al mismo tiempo no se configuran como errores separativos ya que se detectan fácilmente por la ruptura del esquema de rimas de la estrofa. El hecho, pues, de que tanto $M b$ como $M c$ no presenten estas lagunas no significa necesariamente que pertenezcan a una familia diferente con respecto a $\mathrm{Ma}$. El análisis de los errores comunes demuestra, de hecho, la pertenencia de los tres manuscritos a una misma familia: en primer lugar, el error conjuntivo del v. 1621 («El cielo sabe cuánto estimo» en lugar de «El cielo sabe, Conde, cuánto estimo»), que determina hipometría pero no se subsana en ninguno de los tres testimonios. A este hay que añadir los errores compuestos de los vv. 813 y $931,{ }^{11}$ en los que el error parece haberse originado en $M a$ para luego determi-

11. Utilizo la definición de 'error compuesto' en el sentido que explica Ruano de la Haza [1991:499]: «[...] un error compuesto no produce la misma lectura en ambos testimonios, sino que resulta, en el segundo testimonio, en una lectura divergente, la cual sólo puede ser explicada como un intento fallido de corregir la lectura errónea del primer testimonio». Responden a esta definición muchos de 
nar un intento de corrección que comparten $M b$ y $M c$. En el v. 813, donde la Parte lee «que él no me deja casar», $M a$ escribe «que el no me dejar casar»; $M b$ y $M c$ leen «que el no dejarme casar», lectura que no puede derivar de la de la Parte, sino que parece más bien una normalización de la de Ma. En el v. 931, donde la Parte lee «Ese es solo un animal», $M a$, invirtiendo los términos con un error de copia bastante común, escribe «Ese solo es un animal»; $M b$ y $M c$ escriben «Ese solo es animal», corrigiendo la hipermetría de la lectura de $M a$ pero alejándose de la Parte.

Aunque, como hemos dicho en el apartado anterior, no podamos fechar $\mathrm{Mb}$ ni, por tanto, saber a ciencia cierta si es anterior o posterior a $M a$, estos errores apuntan a que es posterior. Muchos más datos afianzan esta impresión. En primer lugar, en $M b$ falta el v. 152 («ya que fue ventura nuestra»), laguna esta que pasa a $M c$ y a las sueltas del XVIII pero que no se encuentra en $M a$; otro error, también compartido con Mc y las sueltas, es el que se observa en el v. 939 («debía» por «te vía»). El primero en teoría no sería separativo con respecto a $M a$ porque puede detectarse fácilmente (y de hecho, lo subsana $M c^{1}$ por contaminación — no sabemos si con $M a$ o con la Parte, con los que coincide su lectura-y lo enmienda por conjetura la más tardía de las sueltas del XVIII). También el segundo error en teoría no es conjuntivo con respecto a $M c$ y las sueltas porque podría haberse generado independientemente siendo paleográfico. Pero, en cuanto a esto último, la colocación cronológica de $M c$ y de las sueltas nos dice que con seguridad el error del v. 939 se generó en $M b$; y el hecho de que $M a$ no presente ni este error ni el del v. 152 (a pesar de que este no pueda clasificarse en puridad como separativo) se añade a otras muchas pruebas de que $M a$ no copia de $M b$. La primera de estas pruebas son los errores propios de $M b$ que $M a$ no presenta:

\begin{tabular}{lll} 
& $M b$ & lectura correcta $(A, M a, M c$ y sueltas $)$ \\
\hline 38 & tantas luces das & tanta luz le das \\
55 & regalo & regalos \\
1951 & muy contento & más contento \\
2065 & de mi tamaño & de su tamaño \\
2332 & mis lágrimas tiernas & qué lágrimas tiernas
\end{tabular}

los casos de sustitución por trivialización que discute Blecua [1983:29] y que se ajustan al conocido concepto de 'difracción del error' propuesto por Contini, que postula una lectio difficilior en el origen de la cadena de errores. En nuestro caso, al contrario, el error inicial no puede decirse que esté motivado por una especial dificultad. 
Se trata de lecturas que no terminan de encajar en el contexto o, peor aún, manifiestan incongruencias (es el caso especialmente de los vv. 1951, 2065, 2332), pero que no se reconocen de inmediato como errores. Por ello creemos que si $M a$ hubiese copiado de $M b$, es probable que los hubiera reproducido.

Otras pruebas son las numerosas lecturas equipolentes propias de $M b$ que no se encuentran en $M a$ y las aún más numerosas lecturas equipolentes e innovaciones que $M b$ comparte con $M c$ y con las sueltas del siglo xviI frente a $M a$, y obviamente frente a la Parte. De estas, merece la pena recordar al menos los dos versos que se añaden después del v. 880, al final del primer acto, puestos en boca de Pelayo («Ay que me muero de hambre! / ¡Ay que de hambre me muero!») en un burdo remedo de la exclamación desesperada de Sancho que cierra el acto en $A$.

Además, y esto añade evidencia a las pruebas ya aportadas, $M b$ comparte con $M c$ y las sueltas otras lecturas muy significativas, que derivan al parecer de las modificaciones realizadas por $M a^{1}$ y $M a^{2}$ en el texto de $M a$. La subsanación de las lagunas de los vv. 684 y 1292 coincide enteramente con las enmiendas realizadas al margen por $M a^{2}$ : «que puesto en su gusto esta» $\mathrm{y}$ «que ya me huuiera casado» (ver figura 2). La falta de los vv. 2076-2077, error común conjuntivo de $M b, M c$ y las sueltas, se da en correspondencia con dos versos irreverentes de Pelayo que se atajan en $M a$ [fig. 8]. La modificación del final, que en $M b, M c$ y en las sueltas elimina la referencia a la fuente histórica en favor de la fórmula más trillada de petición del perdón por las faltas, se realiza por primera vez en $M a$, por la mano que he llamado $M a^{1}$ [fig. 9]. A estos errores e innovaciones, hay que añadir otras lecturas que encuentran su origen en modificaciones de $M a^{1}$ sobre una lección originariamente coincidente con $A .{ }^{12}$ Asimismo, en $M b$ (y luego en $M c$ y en las sueltas) aparecen lecturas correctas en lugar de algunos errores de $A$ que $M a$ repetía pero que luego fueron corregidos por $M a^{1}$ o $M a^{2}$. Descontando las ya mencionadas lagunas de los vv. 684 y 1292, se trata de los siguientes lugares:

12. Estas lecturas se encontrarán en el aparato crítico de mi edición de El mejor alcalde, el rey que se publicará en la Parte XXI de comedias de Lope de Vega, coordinada por Gonzalo Pontón y Ramón Valdés en el marco del proyecto PROLOPE, y corresponden a los vv. 433, 1090, 1293, 1296, 1483, 2010, 2017, 2028, 2409, 2412. 


\begin{tabular}{lll} 
& MaA & lectura correcta \\
\hline 790 & que te ha sucedido & que ha sucedido \\
873 & Yo, mi & Y a mí \\
912 & ya & va \\
1017 & fuentes & frentes \\
1191 & si tienen & y tienen \\
1195 & que miren & que mire \\
1340 & en nobleza & ennoblezca \\
1480 & que & quien \\
1798 & injusto & justo \\
2240 & Habla Pelayo & Habla a Pelayo
\end{tabular}

Por otra parte, algunos errores de $A$ no se enmiendan en $M a$, y sí en $M b, M c$ y las sueltas:

\begin{tabular}{lll} 
& MaA $A$ lectura correcta \\
\hline 143 & respondistes & respondiste \\
217 & tanto & tanta \\
322 & te han & te ha \\
630 & su & sus \\
967 & om. & Deja que pase algún día \\
1200 & la cuchilla & las cuchillas \\
1635 & de historia, & de historias
\end{tabular}

Ninguno de estos errores puede clasificarse como separativo, por lo que no excluyen una derivación directa $M a>M b$; sin embargo, considerado el estado de copia en limpio de $M b$, parece improbable que su copista los corrigiera sobre la marcha, y prefiero pensar que derivara estas correcciones (y tantas otras innovaciones y errores propios de los que ya hemos hablado) de un antígrafo perdido intermedio al que llamaremos $\alpha$. Al contrario, la derivación directa $M b>M c$ sí que la excluyen los errores propios de $M b$ (los ya mencionados vv. 38, 55, 1951, 2065, 2332).

Antes de pasar a examinar la relación entre $M b, M c$ y las sueltas, merece la pena tratar de explicar por qué $M b$ no recoge otras muchas modificaciones de $M a^{1}$ 
(vv. 325, 580, 745, 788, 832, 833, 844, 1022, 1134, 1283, 1355, 1593, 1636, 1704, 1862, 1865), algunas de las cuales sin embargo pasan a $M c$ (vv. 580, 788, 844, 1022, 1134, 1355, 1704). Mi hipótesis es que no todas estas correcciones e innovaciones se realizaron al mismo tiempo en el texto de $M a$; las más antiguas serían las que se recogen en $M b$, mientras que las que no aparecen allí serían posteriores. Pero, al haber seguido circulando el manuscrito $M a$ en el mundo teatral madrileño, es posible que el copista de $M c$ lo cotejara, asumiendo alguna de sus lecturas innovadoras. Se trataría, en este caso, de un fenómeno de contaminación; por otra parte, como veremos al examinar la relación de $M c$ con las sueltas, se dan otras evidencias de fenómenos de contaminación en su texto.

Aún más importante, antes de pasar a examinar las ramas más bajas de la historia textual de $E l$ mejor alcalde, el rey, me parece dilucidar la cuestión de las enmiendas a los errores de $A$ que encontramos en $M a$ y en $M b$. Creo que el análisis del comportamiento de las intervenciones de $M a^{1}$ y $M a^{2}$ en el texto de $M a$ muestra con suficiente claridad las características de la actitud de estos copistas, que mezclan a partes iguales sensibilidad hacia los errores de su texto base y desenfado a la hora de modificarlo por las razones más diversas (en algunos casos, probablemente, por exigencias de censura o autocensura). Lo mismo puede decirse de $M b$, o mejor dicho de su antígrafo $\alpha$, considerando que al lado de las enmiendas aceptables realizan numerosísimas intervenciones innecesarias. Ante esta situación, me decanto por pensar que las enmiendas acertadas de errores de $A$ sean el resultado de correcciones conjeturales. Si para enmendar los errores de $A$ los manuscritos $M a$ y $M b$ hubieran podido acudir a un testimonio de mayor autoridad, no se explicaría por qué siguen compartiendo, sin corregirlos, tres errores de $A$. Dos de estos —el primero muy reconocible porque determina hipometría- pasan tal cual a la tradición posterior:

\begin{tabular}{lll} 
& $A, M a, M b, M c$, sueltas & posible corrección \\
\hline 1058 & a mi & a mí mi (error por haplografía) \\
1346 & a la boca & la boca (error sintáctico)
\end{tabular}

El tercero en cambio da lugar a una cadena de intentos de enmienda sobre los que volveremos. Se trata de la lectura del v. 1392 («las ramas las entrañas de los robles»), cuya incongruencia no se entiende fuera de su contexto. El verso cierra un pasaje en el que Sancho relata al rey lo sucedido cuando don Tello, ante las súplicas 
de Nuño y Sancho que le pedían a Elvira, «tan fiero, /señor, ha respondido /que vieron nuestros pechos el acero / y, siendo hidalgos nobles, / las ramas las entrañas de los robles». Dicha lectura no puede considerarse un error propiamente separativo, porque la falta de sentido del verso en el contexto salta a la vista (de ahí que $M c$ y las sueltas traten de corregirlo); pero por esto mismo es interesante que ni $M a$ ni $M b$ lo corrijan, lo cual me parece indicio de que no contaminaban con otro testimonio que consideraran más fiable. Si esto es así, en la edición crítica podremos aceptar las enmiendas "menores", las que resuelven incongruencias sintácticas así como errores métricos, pero será más conveniente no aceptar las enmiendas "mayores", concretamente la subsanación de las tres lagunas a la altura de los vv. 684, 967, 1292 , porque nada nos garantiza que esos versos que leemos en la tradición posterior a la Parte hayan salido de la pluma de Lope.

3. Como apuntamos al comienzo de este trabajo, la primera impresión suelta de $E l$ mejor alcalde, el rey se publicó en Madrid en 1741 por la imprenta de Antonio Sanz (la llamaré $S$ ). Es, por tanto, bastante anterior al manuscrito $M c$, que se copió presumiblemente hacia 1786 como más pronto, según ya hemos dicho. Las demás sueltas se imprimieron en la segunda mitad del siglo: una en Barcelona por Juan Francisco Piferrer, s.a. (pero después de 1779, año en el que empieza la actividad de este impresor), que llamaré T; una en Madrid en 1792, que se vendía en la Librería de Quiroga (la llamaré $U$ ); y finalmente una en Valencia por los Hermanos de Orga en 1793 (la llamaré V).

$M c$ y las sueltas pertenecen sin duda a una misma familia textual, pues comparten algunas lagunas (vv. 2015-2016, 2315-2328, 2333-2334) y los siguientes errores, además de numerosísimas innovaciones:

\begin{tabular}{lll} 
& Mc STUV & lectura correcta $(\mathrm{A}, \mathrm{Ma}, \mathrm{Mb})$ \\
\hline 15 & habiéndose de hacer & habiendo de nacer \\
161 & decid $\left(\right.$ corr. por $\left.M c^{1}\right)$ & decir \\
341 & alcanza & al anca \\
1384 & que viva protección intente & que viva, protección que intente \\
2046 & de trueno & del trueno \\
2212 & No lo hará & No era
\end{tabular}


Cronológicamente, $M c$ podría derivar perfectamente de $S$, suelta con la que comparte por ejemplo el sistema de acotaciones (que al contrario cambia por completo en $T U V$, cuyas didascalias se apoyan en el mismo sistema de decorados fijos al que nos hemos referido hablando de las correcciones y añadidos realizados en $M c$ por $M c^{1}$ ). Además de los errores comunes ya mencionados, algunas lecturas de $M c$ parecen el resultado de un intento de corrección de errores de $S$ (comunes asimismo a TUV), lo que refrenda la posterioridad de la lectura de $M c$. La primera es la del v. 875 , que se da en un contexto de innovación introducida por $M b$ en la réplica de Pelayo al final del acto I: frente a la lectura de la Parte «Y a mí, señor, / [enséñame] la cocina, que me muero / de hambre; que no he cenado», $M b, M c$ y las sueltas coinciden en sustituir, en el v. 874, «que me muero» con «porque muerto»; ya en el v. 875 divergen, porque, si $M b$ lee (en coincidencia con la suelta $V$ ) «de hambre estoy, que no cené», $S T U$ leen «de hambre estoy, como anoche no cené». La hipermetría, que no se capta enseguida en el texto impreso porque este no reproduce correctamente los versos partidos, sí debía de sentirse en la recitación; y he aquí que $M c$ subsana leyendo «de hambre estoy, no cené anoche». También muy significativo me parece el error compuesto que se da en el v. 1594: donde la Parte, $M a$ y $M b$ leen «venganza con propias manos», STU leen «yo venganza con mis propias manos» con clara hipermetría que $M c$ corrige con «yo venganza con mis manos»: lectura que, como sucede en los casos de error compuesto, no logra restituir la lección originaria sino solo eliminar el problema más evidente. En este caso, la suelta más tardía, $V$, coincide con $M c$, no sabemos si por contaminación o por coincidencia. Finalmente, también es interesante el caso del ya mencionado v. 1392, donde STUV tratan de corregir el poco comprensible original «las ramas las entrañas de los robles», con un aún menos comprensible «los troncos se enternecen de los robles»; probablemente insatisfecho con esta solución, $M c$ lee «nuestras espaldas, troncos de los robles». Es una corrección ingeniosa (de hecho, la enmienda que propongo en mi edición es «las ramas las espaldas de los robles», suponiendo un hipérbaton), que da con una de las palabras necesarias a la comprensión del pasaje (las espaldas de Nuño y Sancho que sufren la paliza propinada por los criados de don Tello), pero que evidentemente deriva de $S$ y no de la Parte, porque, si no, no se explica el mantenimiento de una palabra, «troncos», mucho menos adecuada en el contexto que la original «ramas».

Por otra parte, hay errores comunes de STUV que $M c$ no comparte, algunos de los cuales (vv. 1080, 1082, 1631) pueden interpretarse como separativos por la dificultad de detectarlos como tales errores: 


\begin{tabular}{lll} 
& STUV & $A, M a, M b, M c$ \\
\hline 823 & seis & sus \\
975 & dijo que sí & dijo sí \\
1080 & la mujer & su mujer \\
1082 & del tal & de tal \\
1631 & soy & sol \\
2209 & om. & está a la puerta. ENRIQUE: Ya entró.
\end{tabular}

A estos hay que sumar el verso redundante («Hermano, por vida mía») que STUV añaden, para subsanar la laguna del v. 967, además de la enmienda ya aportada por $M b$ («Deja que pase algún día»).

A su vez, $M c$ presenta numerosas innovaciones propias que lo configuran como testimonio independiente de $S T U V .{ }^{13}$ Omite, además, los vv. 1033-1068, añade uno después del v. 340, y, aún más interesante, en el final incrusta una réplica de don Tello en la que este reconoce su error (después del v. 2406: «Llegó, Cielos, el castigo / de mi tirana soberbia») y otra del rey que subraya el valor pedagógico del castigo del noble rebelde («Conde, disponed la vuelta / para mañana a León, / y sirva a todos de enmienda / este caso verdadero»).

Las sueltas más tardías (TUV), al contrario, comparten como ya hemos dicho todos los errores de $S$, pero, a su vez, presentan otros errores comunes:

\begin{tabular}{lll} 
& TUV & $A, M a, M b, M c, S$ \\
\hline 460 & guardaba (hipermetría) & guarda \\
775 & el alba & del alba \\
1316 & Señor, no ha quedado & No ha quedado \\
1317 & ya ninguno (hipermetría) & ninguno
\end{tabular}

Especialmente interesante es la lectura de $T U V$ en el v. 1592, que muestra una clara independencia con respecto a los manuscritos que conocemos y, al contrario, la dependencia de $S$. Donde $M a, M b$ y $M c$ leen correctamente «No soy quien soy», y $S$

13. Se verán en el aparato crítico de mi edición en los vv. 5, 95, 158, 174, 210, 265, 323, 614, 815, 875, 1023, 1360, 1392, 1523, 1617, 1620, 1770, 1914, 1924, 2121, 2350, 2408. 
(como la Parte) «Yo soy quien soy», TUV leen «Que yo soy quien soy», lo que determina hipermetría con la exclamación siguiente de Pelayo («iSan Macario!») que completa el verso partido. Para resolver el problema, $V$, la más tardía de las sueltas, cambia esta exclamación por «iSan Marcos!», claro ejemplo de error compuesto que muestra sin lugar a dudas la dirección del error. En otros lugares del texto $V$ muestra una disposición a la enmienda, como cuando trata de restaurar la laguna del v. 152 , común a $M b, M c$ y $S T U$, con el verso «ya con intención siniestra»; o cuando corrige la ya recordada lectura hipermétrica de $S T U$ en el v. 875 («como anoche no cené»); o cuando corrige la lectura de $S T U$ en el v. 1326 («y divina observación de sus leyes»), cuyo ritmo cojeante denuncia el error, con «y divina observancia de sus leyes», que soluciona el problema métrico pero no da con la lectura correcta que es la de la Parte («divina observación de santas leyes»). Por otra parte, $V$ presenta algunos errores propios, los más importantes de los cuales afectan a los nombres de los protagonistas: en el reparto, don Tello de Neyra se transforma en don Tello de Veyra, y Nuño de Aibar en Nuño de Albar, prueba de una mala lectura del original de imprenta, siendo ambos errores claramente paleográficos. En un contexto de sustancial identidad del sistema de acotaciones de $T U V$ frente al de $S$ (que repite el de $A$ ), $V$ introduce además algunas innovaciones en las acotaciones. El texto de $V$, pues, confirma el dato cronológico que nos proporciona la fecha de impresión, por lo que podemos ver en esta suelta el tramo final de la historia textual de El mejor alcalde, el rey que hemos seguido hasta aquí.

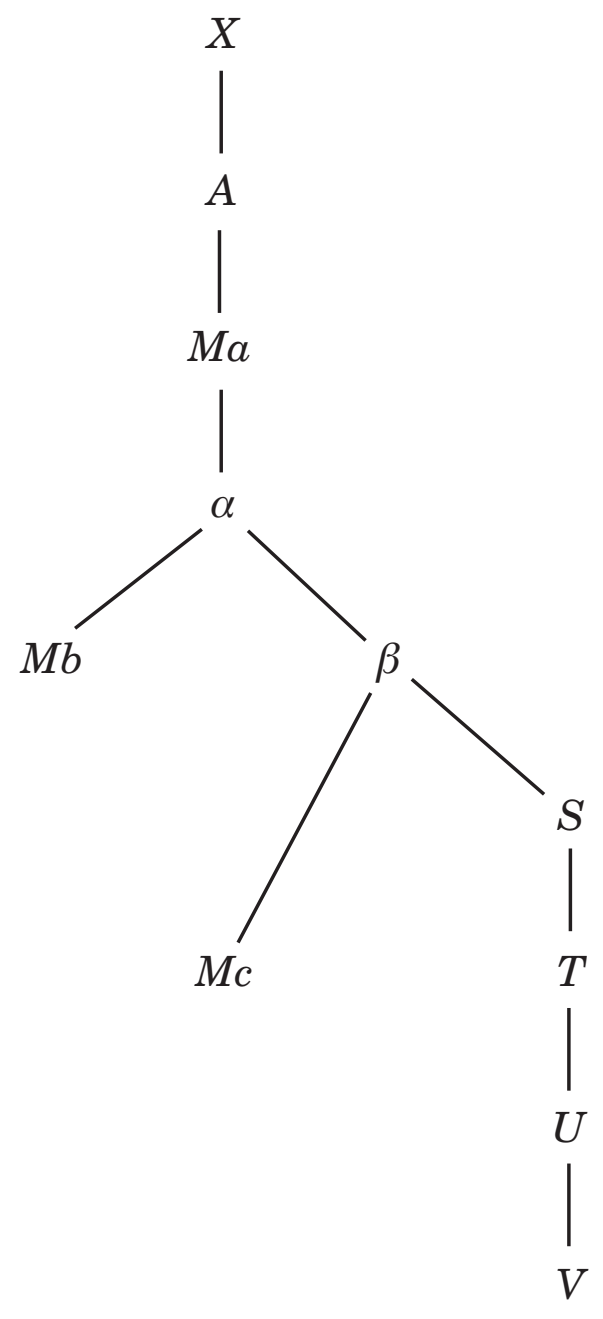


4. Aunque abarca las etapas fundamentales de la transmisión textual de $E l m e$ jor alcalde, el rey entre finales del siglo XVII y finales del siglo XVIII, el stemma anterior no da cuenta de algunos testimonios tardíos cuyo interés reside básicamente en mostrarnos al vivo, como ya hemos visto en $M a$ y $M c$, el trabajo de las compañías con el texto teatral, el desenfado con que este texto se corrige, se modifica, se contamina. Me refiero a los tres apuntes impresos que se conservan, como $M a$ y $M c$, en la Biblioteca Histórica Municipal de Madrid.

El apunte identificado con la signatura Tea-1-46-6, b minus $\left(S^{1}\right)$ consiste en el texto de la suelta $S$ al que el apuntador aportó diversas modificaciones manuscritas. En la portada, tras la indicación «2 Apunto» corregida luego en «3 Apunto», se lee «esta es una de las que compuso Lope disparatada sin culpa suya» [fig. 10]. Al vuelto, se escribe la lista de las dramatis personae con la asignación de los papeles: dos de los nombres que allí figuran coinciden con los que se leen en el vuelto de la portada del primer acto de $M c$, coincidiendo asimismo los papeles: el Rey lo hará Pinto, don Tello lo hará Ponce, Nuño lo hará Baca [fig. 11]. Aunque otras asignaciones, especialmente la del papel de Sancho, son diferentes, este dato prueba la vinculación entre $M c$, que, como hemos visto, se copió en el seno de la compañía de Manuel Martínez, y $S^{1}$. Y de hecho, sabemos que Carretero, Roldán, García, Baca, Hernando y Querol formaban parte en 1799 de la compañía de Francisco Ramos, yerno de Manuel Martínez, que heredó a la muerte de este la dirección de su compañía (Soria Tomás 2020:582-583). Y sabemos, por los datos que nos proporcionan Andioc y Coulon [1996:474], que dicha compañía representó El mejor alcalde, el rey en diciembre de 1799, por lo que es probable que el apunte que nos ocupa se haya utilizado para esta función.

El texto de $S$ está plagado de atajos en $S^{1}$, pero, más allá de estos recortes (que, añadidos a los propios de $S$, reducen aún más la duración de la pieza de Lope), las correcciones no son muchas, y la mayoría de las indicaciones manuscritas tienen que ver con elementos de decorado y con la entrada o salida de los actores al tablado. El interés de las pocas correcciones reside en que la mayoría de las veces revelan una contaminación con $M c$, en un estadio de este manuscrito que ya contenía las intervenciones de $M c^{1}$, según se ve en los ejemplos siguientes: 


\begin{tabular}{|c|c|c|}
\hline & $S$ & $S^{1}$ \\
\hline 3 & que el Sil & el Sil $(=M c)$ \\
\hline 152 & om. & ya que fue ventura nuestra $\left(=M c^{1}\right)$ \\
\hline 158 & y supuesto que pobres & aunque humildes y pobres $(=M c)$ \\
\hline 210 & con alguna espada & con mayor soldada $(=M c)$ \\
\hline 256 & por ir & por no ir $\left(=M c^{1}\right)$ \\
\hline 464 & porque & por si $\left(=M c^{1}\right)$ \\
\hline 580 & soy algo o que lo fui & soy hidalgo y lo fui $(=M c)$ \\
\hline 788 & en la calle & en el campo $\left(=M c^{1}\right)$ \\
\hline 1360 & pucheros & extremos $(=M c)$ \\
\hline 2209 & om. & está a la puerta. EnR.: Ya entró $(=M c)$ \\
\hline 2258 & y lo que pasa & y lo que pesa $\left(=M c^{1}\right)$ \\
\hline
\end{tabular}

Sin embargo, el cotejo del apuntador no fue sistemático, porque en muchos lugares en los que la lectura de $S$ diverge de la de $M c$ el texto de la suelta no muestra correcciones; al contrario, hay casos en los que las enmiendas parecen el resultado de una iniciativa autónoma del apuntador, porque no dependen de ningún texto conocido. Por ejemplo, en el v. 1049, correspondiente a una amplia laguna de $M c$, se corrige la hipermetría de la lectura de $S$ («Salí, señor, volviendo a los desiertos prados») tachando el verbo en gerundio y, al tiempo que se restaura la medida del endecasílabo, alejándose aún más de la lectura de $A$ («Luego, volviendo a los desiertos prados»). O también, en el ya discutido v. 1392, se enmienda la lectura de $S$ de forma original («en la espalda la rama de los robles»), no coincidente con la de $M c$ («nuestras espaldas, troncos de los robles») y que se acerca más a la posible lectura correcta, ya desfigurada en $A$. En este cuadro, la ocasional coincidencia con $M a$ de la enmienda en el v. 4, que transforma «llevar las faldas» en «nevar las faldas» (mientras $M c$ leía «lavar las faldas») debe considerarse una mera coincidencia, propiciada por la mención de las montañas en el v. 2.

Los dos apuntes Tea 1-46-a1 y Tea 1-46-a2 son dos ejemplares de la suelta madrileña de $1792(U)$ con diversas modificaciones manuscritas. Tea 1-46-a2 es un apunte primero, por lo que lo llamaremos $U^{1}$ : lleva en la portada la indicación «Oy dia 20 de Enero de 1804», fecha que coincide con la que recogen Andioc y Coulon [1996:509] como primera representación de El mejor alcalde, el rey en el teatro de 
los Caños del Peral para ese mes, sin que se indique la compañía. Sin embargo, la coincidencia de algunos nombres de actores con los de los dos elencos que se encuentran en $M c$, y con el que se encuentra en $S^{1}$, lleva a conjeturar que pudo tratarse de la misma compañía que había sido de Manuel Martínez y que a la altura de 1804 dirige su yerno Francisco Ramos desde hacía nueve años. Volvemos a encontrar a [Antonia] Prado en el papel de Elvira, a [Josefa] Luna como Feliciana, ${ }^{14}$ a Gertrudis Torre como Juana; aunque en papeles diferentes, volvemos a encontrar los nombres de Roldán y de Contador, junto con otros nuevos, uno de los cuales es el de Isidoro Máiquez, a quien inicialmente se le confía el papel de don Tello, en un segundo momento sustituido por Ronda [fig. 12]. Las iniciales del apuntador parecen las mismas de Fermín del Rey, el copista de $M c$; y de hecho, según la ficha catalográfica de la Biblioteca Histórica Municipal de Madrid, las iniciales que figuran en las portadas de los actos son «FR» (aunque a mí me parece ver también una «A» embebida) [fig. 13]. También en el caso de estos dos apuntes, la relación con $M c$ es clarísima, y aún más estrecha que en el de $S^{1}$. Además de las correcciones de este apunte (de las que solo falta la enmienda de la laguna del v. 2209), en muchas más lecturas se corrige el texto de $U$ de acuerdo con $M c$ :

\begin{tabular}{lll} 
& $U$ & $U^{1}$ \\
\hline 4 & llevar & lavar $(=M c)$ \\
5 & dais sustento & dando aliento $(=M c)$ \\
95 & Eso, ¿cúya culpa ha sido? & Esa culpa, ¿cúya ha sido? $(=M c)$ \\
155 & Di. & Pues di. $(=M c)$ \\
1022 & divino & heroico $(=M c)$ \\
1023 & te vine a hablar & para casarme $(=M c)$ \\
1828 & que te doy & de ti hoy $\left(=M c^{1}\right)$ \\
2121 & bastante & segura $(=M c)$ \\
2378 & que os crie en aquesta tierra & el ser yo quien por él ruega $\left(=M c^{1}\right)$
\end{tabular}

14. En ambas ocasiones me decanto por pensar que se trataba de Josefa, hermana de la más famosa Rita Luna, porque el papel de Feliciana es un papel de segunda dama (y Josefa Luna ya en la temporada 1792-1793 era segunda dama de la compañía de Martínez), mientras que a la altura de 1804 Rita Luna era una actriz famosísima, mucho más que su hermana, y no se conformaría con un papel de segunda dama. Sobre Rita Luna pueden verse las abundantes notas de Sánchez Estevan [1915:217-270]. 
Además, en correspondencia con la laguna de los vv. 1065-1072 (una parte de la perorata con la que Sancho en el segundo acto relata su desgracia a don Tello tratando de conmoverlo para que le devuelva a Elvira), $U^{1}$ pega una banderilla sobre los versos que en la suelta $U$ sí aparecen, y copia en su lugar los que la mano $M c^{1}$ había añadido al margen para subsanar al menos en parte la laguna : «No fuera estraño aquí el hablar con ira, / pero no creo tal de tu arrogante / pecho, que a tus vasallos ama y mira / como padre amoroso y vigilante» [fig. 14]. Asimismo, en el caso del ya muy comentado v. 1392 , la corrección del apuntador no repite la de $S^{1}$, más acertada, sino exactamente la lectura de $M c$ («nuestras espaldas, troncos de los robles»). El apunte segundo (Tea 1-46-a1), que llamaré $U^{2}$, presenta las mismas correcciones que $U^{1}$ y desde el punto de vista textual no aporta ninguna novedad. A la luz de los datos que nos proporciona el cotejo de estos apuntes (tanto $S^{1}$ como $U^{1}-U^{2}$ ) podemos afirmar que $M c$ siguió siendo utilizado en el seno de la misma compañía para la que se copió inicialmente, como más pronto en 1786.

5. Todos los testimonios que hemos examinado a lo largo de estas páginas presentan las características típicas de los textos teatrales que han corrido por los tablados: recortes, innovaciones, correcciones por conjetura más o menos acertadas, enteros pasajes modificados, evidencias de contaminación... Aunque mi intención era la de centrarme sobre todo en la tradición de El mejor alcalde, el rey posterior a la Parte, no estará de más decir que no podemos de ningún modo excluir que también el texto de la Parte haya sido objeto de intervenciones parecidas. Hay que recordar que entre la fecha posible de composición (1620-1622) y la fecha de publicación de la Parte XXI (1635) median más de diez años durante los cuales la obra fue representada no sabemos cuántas veces; la reducida extensión (2412 versos), lo extraño del cortísimo pasaje en sueltos (solo seis versos) que abre el tercer acto y que puede ser el resultado de un atajo que recortara antecedentes históricos, además de los errores y lagunas propios, son indicios de que este texto no coincide seguramente con el que escribió Lope, aunque sin duda se le acerque más que el de todos los testimonios posteriores.

Estos, a su vez, al paso que tratan de corregir los errores y lagunas de $A$, introducen un sinfín de nuevos errores, de nuevas lecturas más o menos acertadas, y siguen recortando, recortando... hasta dejar el texto en mucho menos que los 2412 
versos de $A$. El análisis de los errores nos ha mostrado cómo, probablemente, las intervenciones de $M a^{1}-M a^{2}$ fueron el origen de las modificaciones textuales que pasan a $M b$, a las sueltas y a $M c$; y cómo posiblemente $M c$ contaminara con $M a$ para asumir algunas de las correcciones más tardías realizadas en el texto originario de este manuscrito. También nos ha mostrado la existencia probable de un intermediario perdido que transmitió a $M c$ y a las sueltas más errores e innovaciones. Todo ello es buen ejemplo de los avatares que el texto teatral corría durante su vida en el seno de las compañías; es ejemplo de una actitud ante el texto teatral en la que se mezclaban sensibilidad y desatención por el error, y sobre todo desenfado. Lo que nos muestran los textos que hemos analizado es una reescritura mínima pero constante e invasiva, que no vacila en cambiar palabras y pasajes, o incluso añadirlos. Por ello, como ya he dicho arriba, lo que aprendemos del estudio de la historia textual de El mejor alcalde, el rey nos debe volver cautelosos, muy cautelosos, a la hora de aceptar, para enmendar los errores de $A$, lecturas que tan bien pueden ser acertadas como fruto del ingenio del apuntador de turno.

Por otra parte, el examen detenido de los avatares que el texto de Lope sufrió durante su dilatada trayectoria en los escenarios a lo largo del periodo considerado —periodo que abarca más de un siglo, desde 1692 hasta 1804- nos dice también otras muchas cosas interesantes. La primera es la sustancial continuidad cronológica entre la refundición realizada por Dionisio Solís en 1810 y las representaciones del drama de Lope que se llevaron a escena con gran frecuencia en los teatros madrileños desde el comienzo del siglo XVIII. ${ }^{15}$ Dicha continuidad atañe también a la actitud hacia el texto de Lope tal como se consigna en la Parte XXI: una actitud que no vacila ante la manipulación, la innovación, la reescritura. En conexión con esta primera observación, la historia textual de El mejor alcalde, el rey tal como la hemos venido estudiando hasta aquí puede servir asimismo para reconsiderar en su justo valor la tarea editora de Juan Eugenio Hartzenbusch. No es baladí, apenas en 1853 - cuando la refundición de Solís, lo recordamos, se siguió representando con gran éxito hasta al menos 1846-, la empresa de tratar de restituir el texto de $E l$ mejor alcalde, el rey según la lección de la Parte XXI, depurándolo de las lagunas

15. Digo que se trata de representaciones del drama de Lope, y no de la refundición de Martínez de Meneses, porque me parece que los datos que aportan los testimonios examinados en estas páginas permiten afirmarlo con cierta seguridad, sin perjuicio de que la refundición de Martínez de Meneses haya podido representarse en algunas ocasiones. 
introducidas por las sueltas y de alguna de sus innovaciones; y si es cierto que la proclividad a la enmienda de Hartzenbusch y su desenvuelta apropiación de lecturas de las sueltas no responde a los modernos criterios ecdóticos, y sus elecciones a menudo son discutibles, también es cierto que su edición representa un paso adelante en la recuperación de un texto de El mejor alcalde, el rey más cercano a la que fuera la voluntad de Lope, más cercano sin duda que el de las sueltas del xviII.

Por otra parte, hay que considerar que con toda probabilidad estas procedían, como los manuscritos $M a, M b$ y $M c$, del mundo del teatro, y es improcedente comparar la actitud hacia el texto del hombre de teatro con la del editor. De hecho, a nadie se le ocurriría hoy juzgar con el mismo metro una edición académica y una versión para una puesta en escena, porque responden a criterios totalmente diferentes. Lo que busca el versionador hoy es exactamente lo que buscaban el autor de comedias y su apuntador en el pasado: hacer que el público comprenda el texto, modificando pasajes de comprensión dudosa y actualizando el léxico; evitar que el público se aburra, abreviando el texto y eliminando pasajes de eficacia dramática poco segura. El problema para los editores filólogos es que con frecuencia tenemos que trabajar con textos que - no nos llamemos a engaño- no son exactamente los que salieron de la pluma del dramaturgo sino, más bien, los que salieron de la pluma del apuntador; versiones, en suma, para una función determinada. Y esto vale también, en amplia medida, para los textos publicados en las Partes, aunque muchas veces, como en el caso de El mejor alcalde, el rey, sean lo más cercano que tenemos al original del dramaturgo. Hay que asumirlo, conscientes de que la transmisión del texto teatral estuvo vinculada desde el comienzo a las exigencias de las compañías y no a las de la filología, y saber asumir las decisiones oportunas teniendo en cuenta que a veces, cuando queramos acudir a testimonios más tardíos para enmendar errores de la edición príncipe, lo que estaremos corriendo el riesgo de editar será una conjetura del apuntador en lugar de la lectura original. 


\section{BIBLIOGRAFÍA}

Aguerri Martínez, Ascensión, «La catalogación de los apuntes de teatro en la Biblioteca Histórica Municipal», Revista General de Información y Documentación, XVII 1 (2007), pp. 133-164.

Andioc, René, y Mireille Coulon, Cartelera teatral madrileña del siglo XVIII (17081808), Presses Universitaires du Mirail, Toulouse, 1996, 2 vols.

ARTELOPE. Base de datos y argumentos del teatro de Lope de Vega, dir. Joan Oleza, en línea, <http://artelope.uv.es/>. Consulta del 10 de julio de 2021.

BleCUA, Alberto, Manual de crítica textual, Castalia, Madrid, 1983.

CATCOM = FerRer VALLS, Teresa et al., CATCOM. Base de datos de comedias mencionadas en la documentación teatral (1540-1700), 2012-2021, en línea, <http:// catcom.uv.es>. Consulta del 10 de julio de 2021.

CoE, Ada M., Catálogo bibliográfico y crítico de las comedias anunciadas en los periódicos de Madrid desde 1661 hasta 1819, The Johns Hopkins Press-H.Milford, Oxford University Press, Baltimore, Londres, 1935.

Cotarelo y Mori, Emilio, Isidoro Máiquez y el teatro de su tiempo, Imprenta de J. Perales y Martínez, Madrid, 1902.

DICAT = FERRER VALLS, Teresa, dir., Diccionario biográfico de actores del teatro clásico español (DICAT), Reichenberger, Kassel, 2008.

Doménech Rico, Fernando, «La criada se hace señora. Un tema goldoniano en el teatro español del XVIII», Cuadernos de Ilustración y Romanticismo, XX (2014), pp. 27-42.

Grau SANz, Mariano, El teatro en Segovia, Instituto Diego de Colmenares, Segovia, 1958. Manos. Base de datos de manuscritos y copistas teatrales, dirs. M.R. Greer y A. García Reidy, en línea, <https://www.manos.net/>. Consulta del 10 de julio de 2021.

Pérez y Pérez, María Cruz, Bibliografía del teatro de Lope de Vega, CSIC, Madrid, 1973.

Regueiro, José M., y Arnold G. Reichenberger, Spanish drama of the Golden Age. A catalogue of the manuscript collection at the Hispanic Society of America, The Hispanic Society of America, Nueva York, 1984.

Ribao Pereira, Montserrat, «Acerca de los apuntes y sus posibilidades en el estudio del teatro romántico español (1835-1845)», España Contemporánea, XII 2 (1999), pp. 67-86. 
Ruano de la Haza, José María, «Introduction» a Pedro Calderón de la Barca, Cada uno para sí, a critical edition, with introduction, including a study of the transmission of the text, and notes, Reichenberger, Kassel, 1982, pp. 3-141.

RUANo DE LA HAZA, José María, «La edición crítica de un texto dramático del siglo XVII: el método ecléctico», en Crítica textual y anotación filológica en obras del Siglo de Oro, eds. I. Arellano y J. Cañedo, Castalia, Madrid, 1991, pp. 493-517.

RUBio JiMÉNEZ, Jesús, «El arte escénico en el siglo XIX», en Historia del teatro español, II. Del siglo xVIII a la época actual, coord. J. Huerta Calvo, Gredos, Madrid, 2003, pp. 1803-1852.

SÁnchez Estevan, Ismael, Rita Luna. Comedia dramática en un prólogo y cuatro actos, con notas, Renacimiento, Madrid-Buenos Aires, 1915.

SHERGOLD, Norman D., y John E. VAReY, Teatros y comedias en Madrid: 1687-1699. Estudio y documentos, Tamesis Books, Londres, 1979.

Soria Tomás, Guadalupe, «El saber del actor español en el siglo xvIII. La expresión de las pasiones en los tratados de declamación», CESXVIII, XXX (2020), pp. 567-592. 


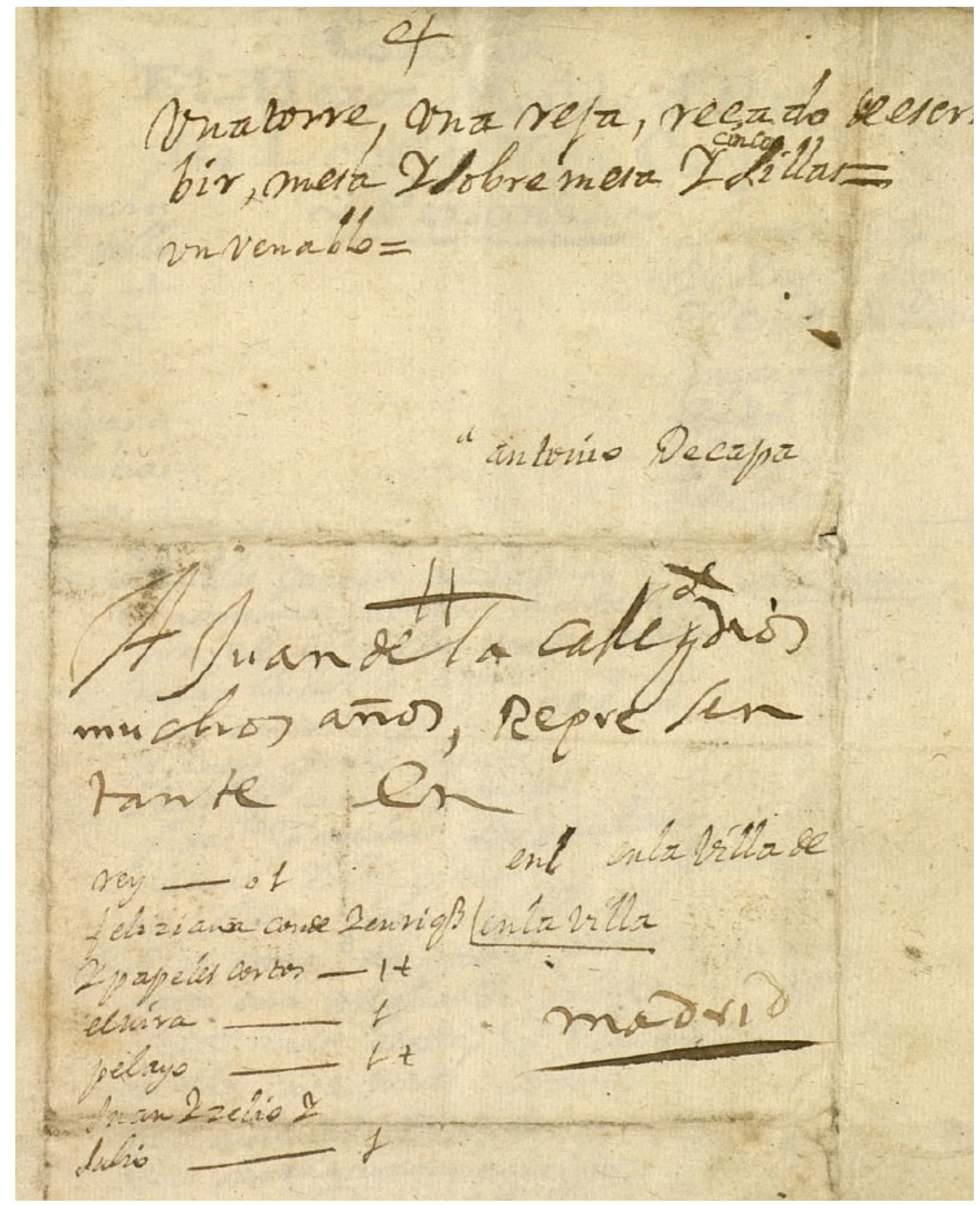

Figura 1. Sobrescrito de la carta en que está encuadernado el manuscrito Tea-49-6,B (Biblioteca Histórica Municipal de Madrid). 

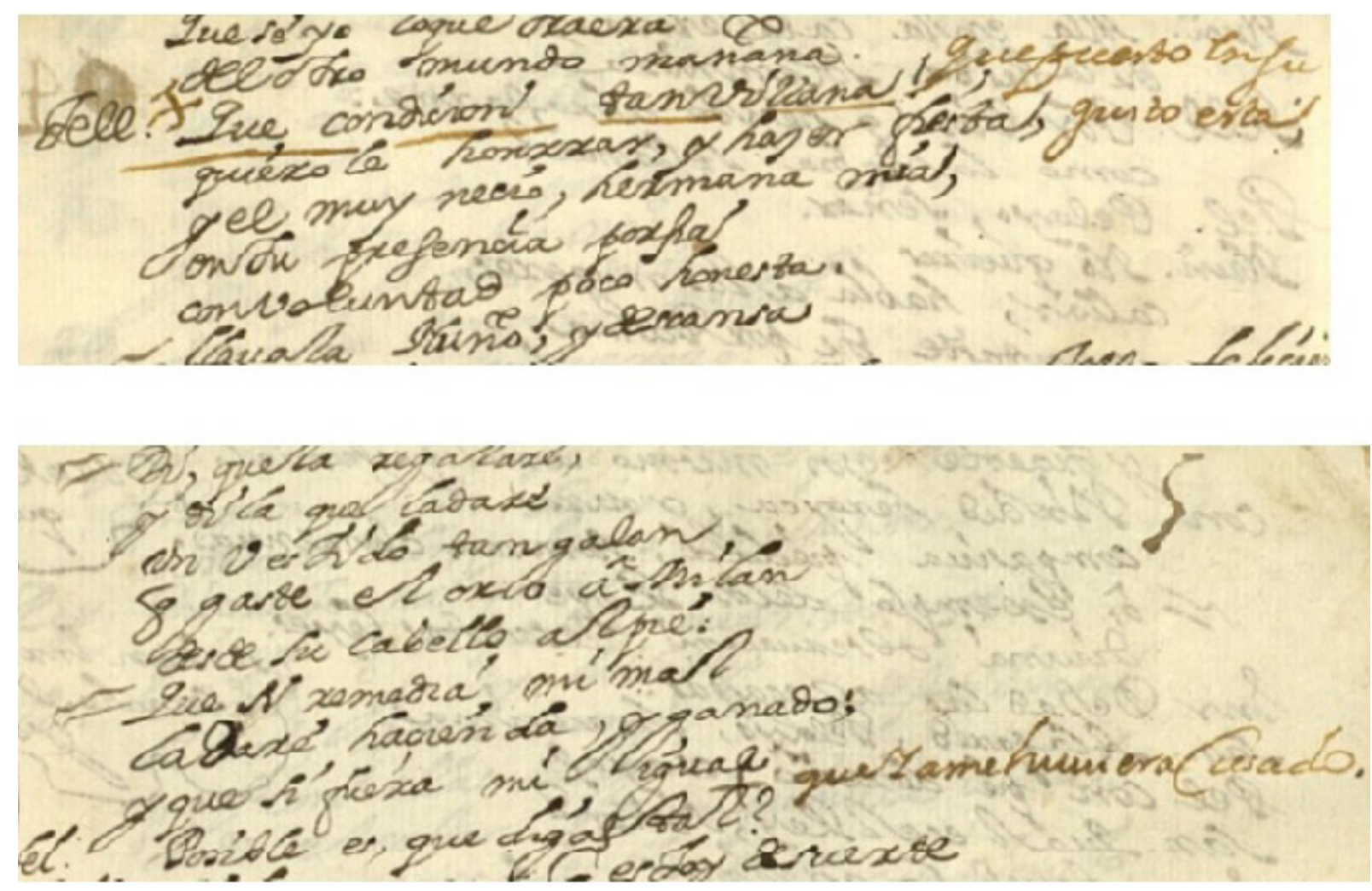

Figura 2. Enmiendas de la mano $M a^{2}$ en los ff. $4 \mathrm{v}$ de la I jornada y $5 \mathrm{r}$ de la II jornada del manuscrito Tea-49-6,B (Biblioteca Histórica Municipal de Madrid). 


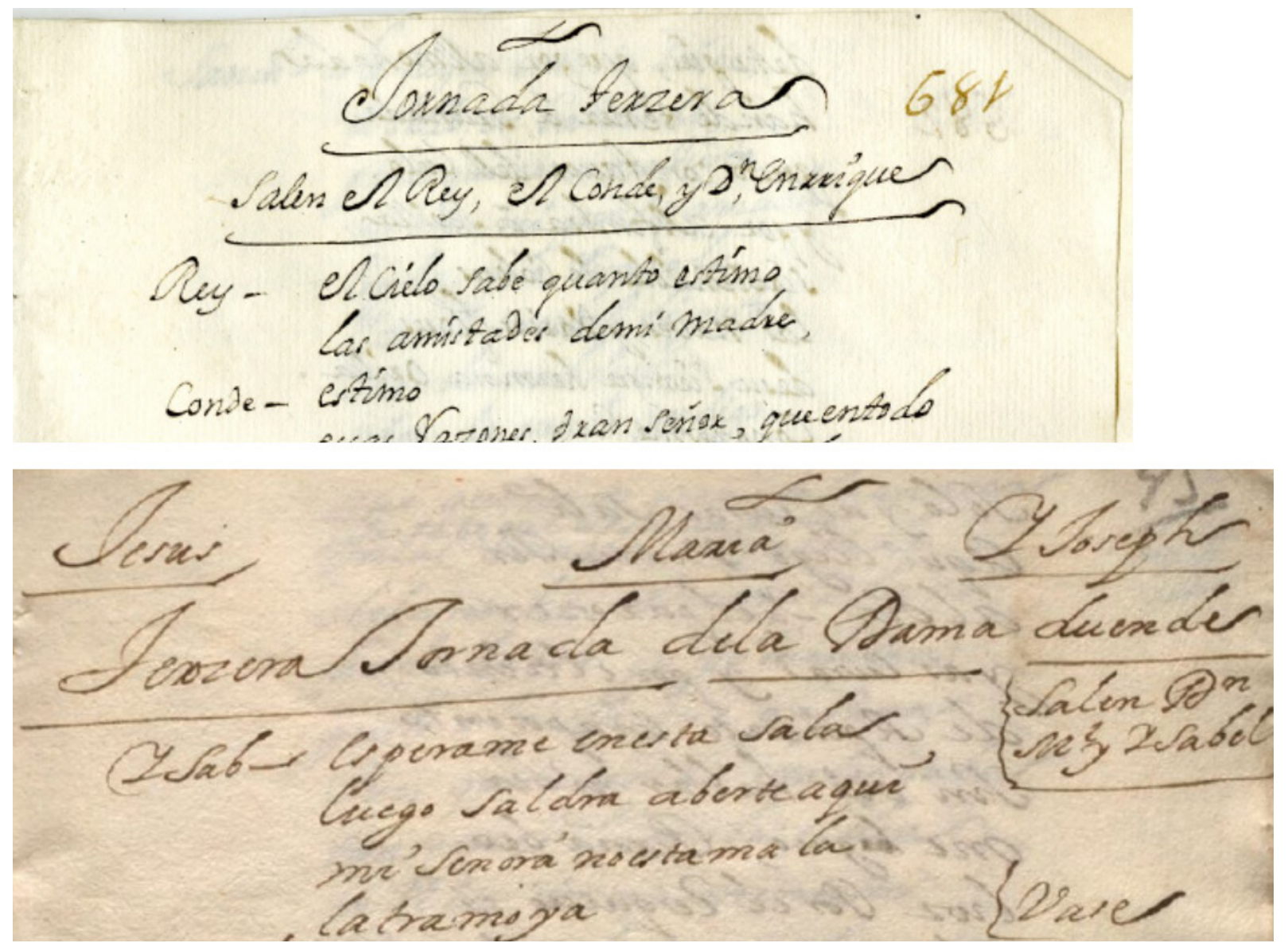

Figura 3. Comparación entre el encabezamiento de la III jornada del manuscrito B2640

(Biblioteca de la Hispanic Society of America) y el de la III jornada del manuscrito 16.622 de la Biblioteca Nacional de España (La dama duende, de Calderón de la Barca). 

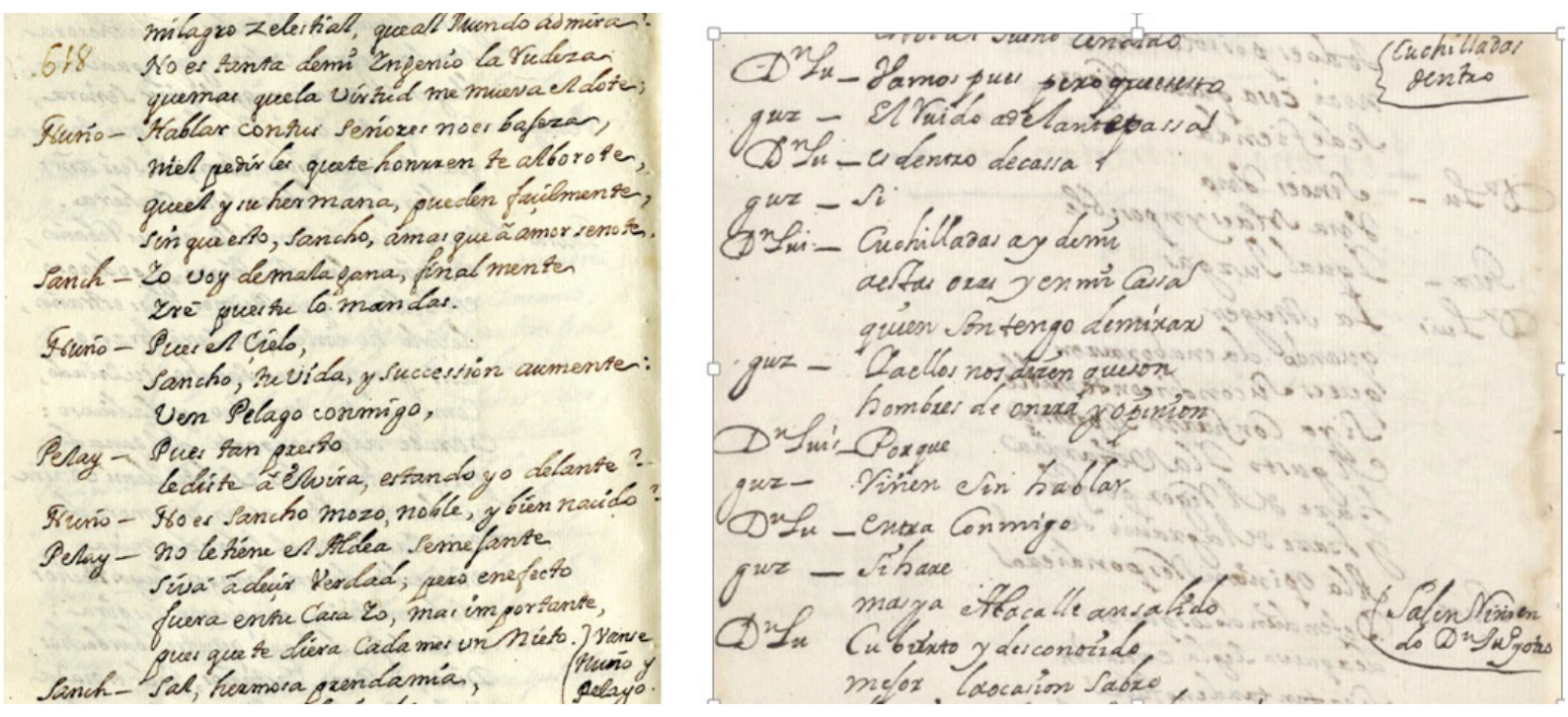

Figura 4. Comparación entre la p. 618 del manuscrito B2640 (Biblioteca de la Hispanic Society of America) y el f. 2v. del manuscrito 15.633 de la Biblioteca Nacional de España (Bien vengas mal, si vienes solo, de Calderón de la Barca).

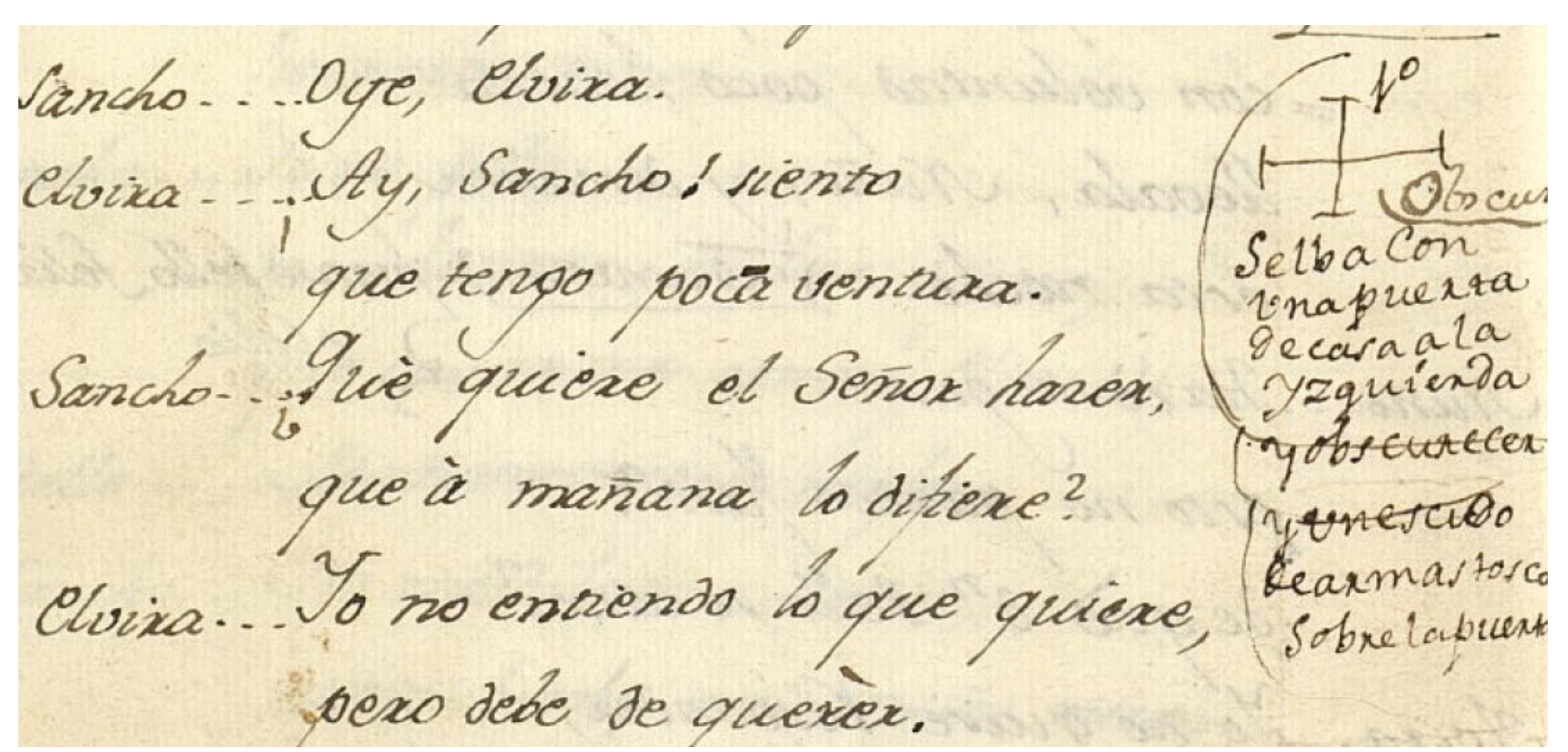

Figura 5. Anotación de decorado e iluminación realizada por la mano $M c^{1}$ en la p. 7 de la I jornada del Ms. Tea-49-6,A (Biblioteca Histórica Municipal de Madrid). 


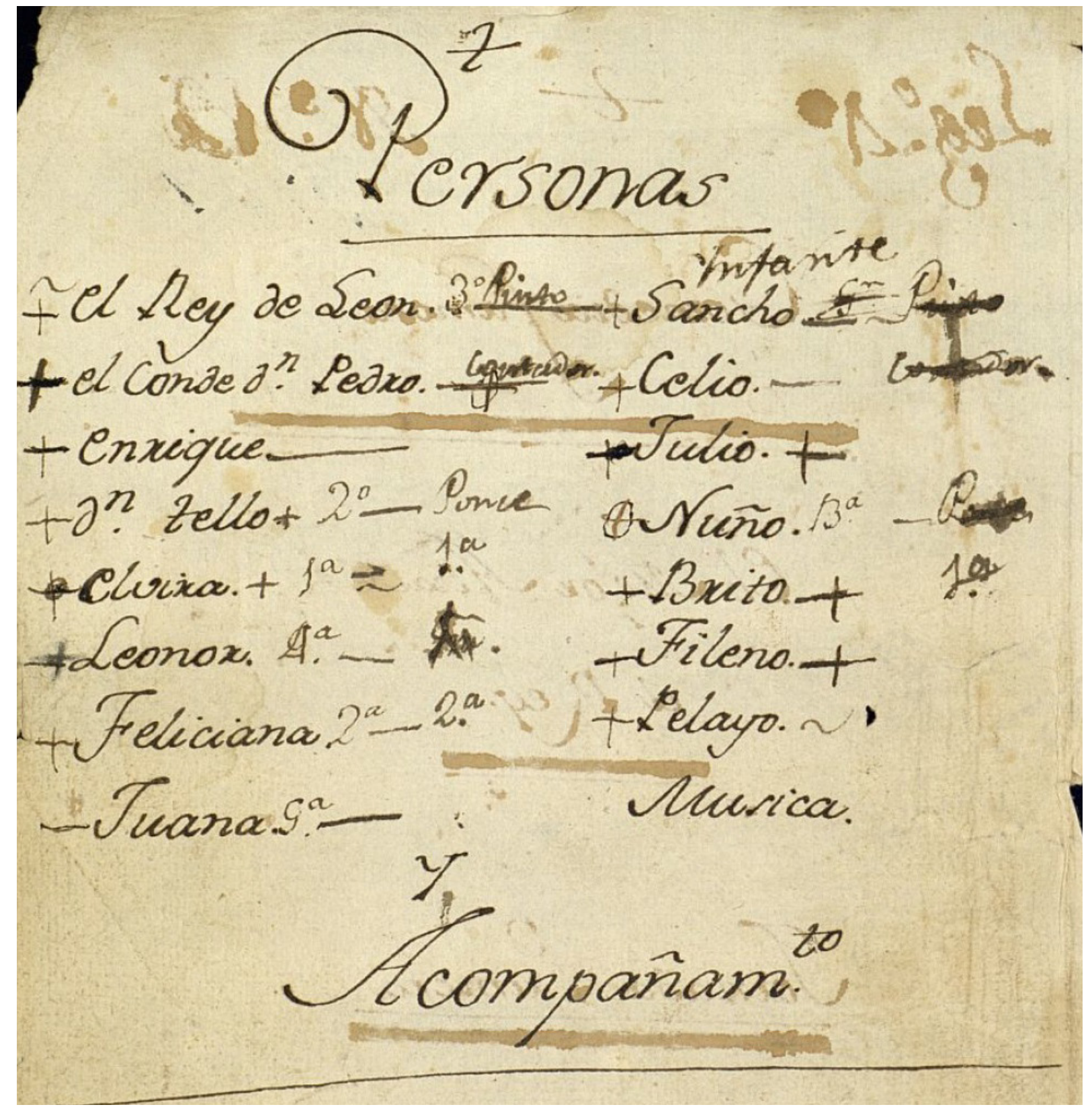

Figura 6. Reparto y elenco parcial de actores, vuelto de la portada de la I jornada del Ms. Tea-49-6,A (Biblioteca Histórica Municipal de Madrid). 


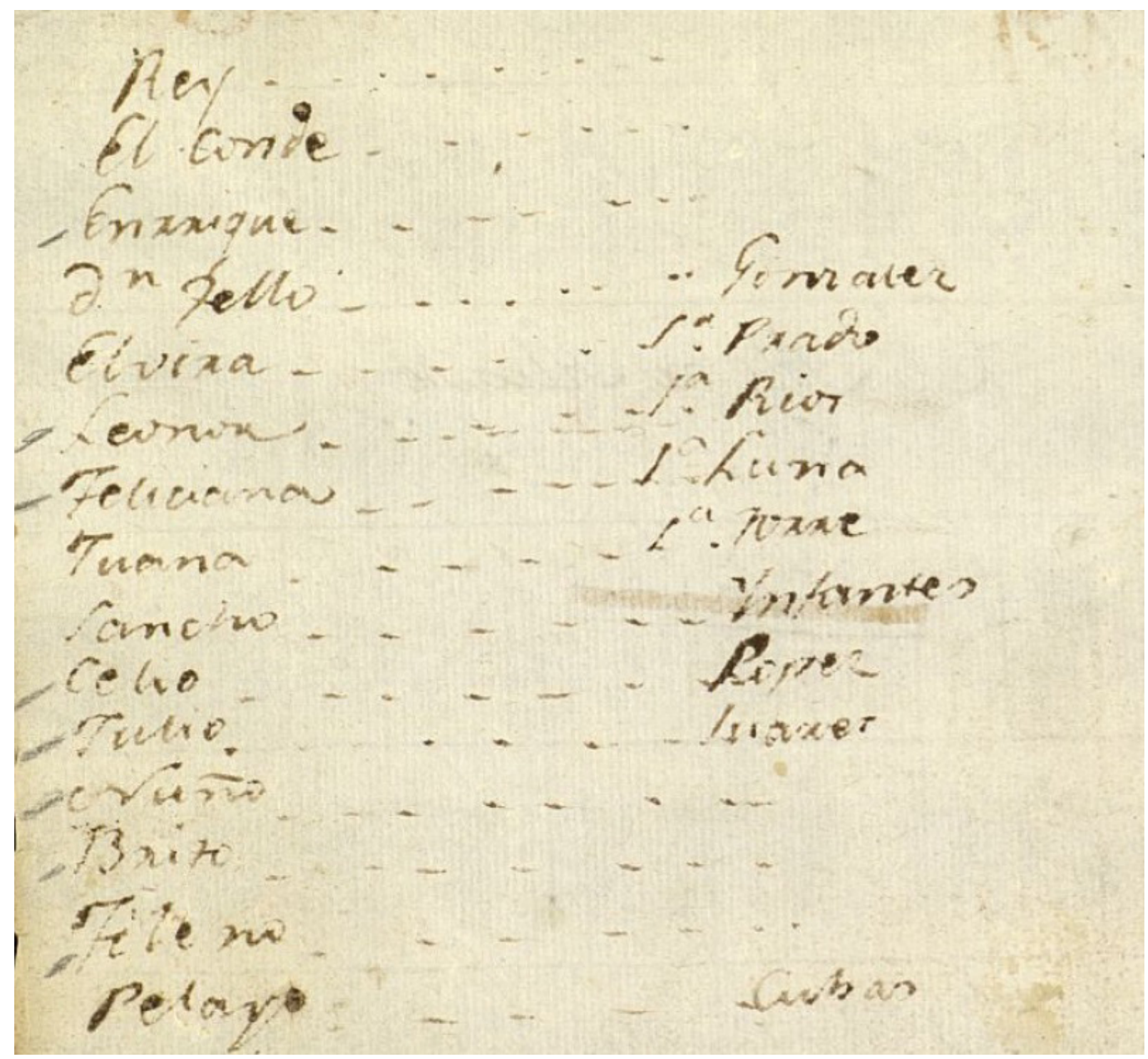

Figura 7. Reparto y elenco de actores, escrito por la mano $M c^{2}$ al vuelto de la portada de la III jornada del Ms. Tea-49-6,A (Biblioteca Histórica Municipal de Madrid). 


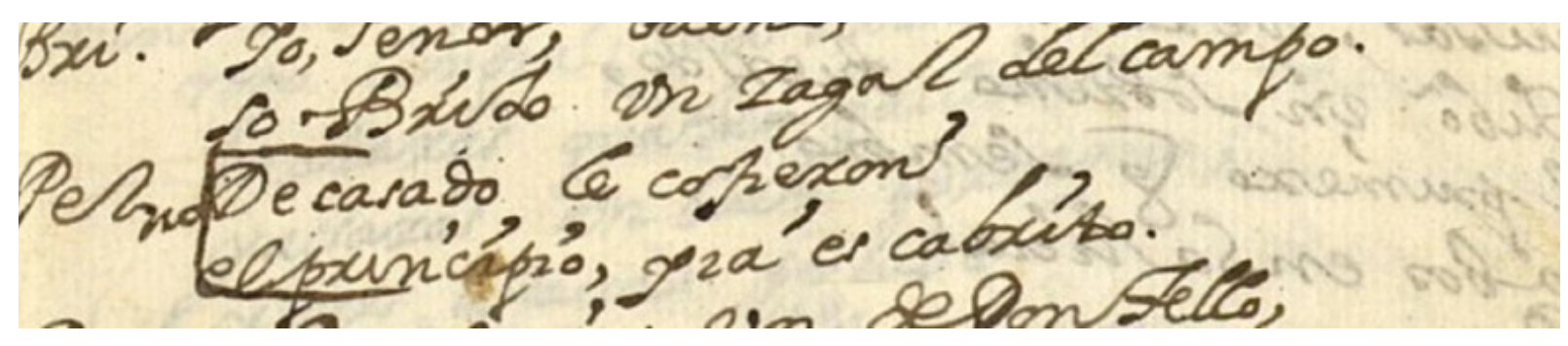

Figura 8. Atajo realizado en el f. 6r de la III jornada en el manuscrito Tea-49-6,B (Biblioteca Histórica Municipal de Madrid).

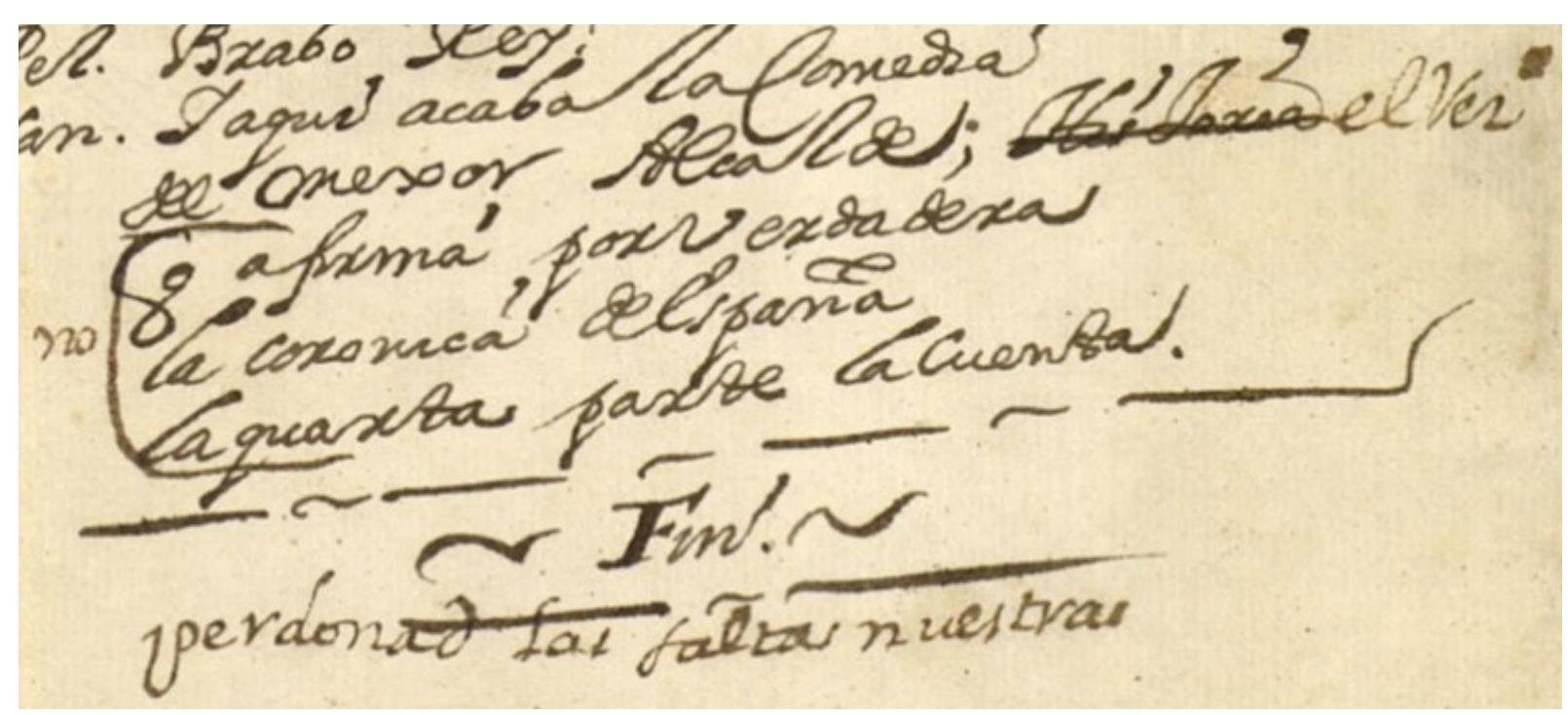

Figura 9. Modificación del final realizada por la mano $M a^{1}$ en la última página de la III jornada en el manuscrito Tea-49-6,B (Biblioteca Histórica Municipal de Madrid). 


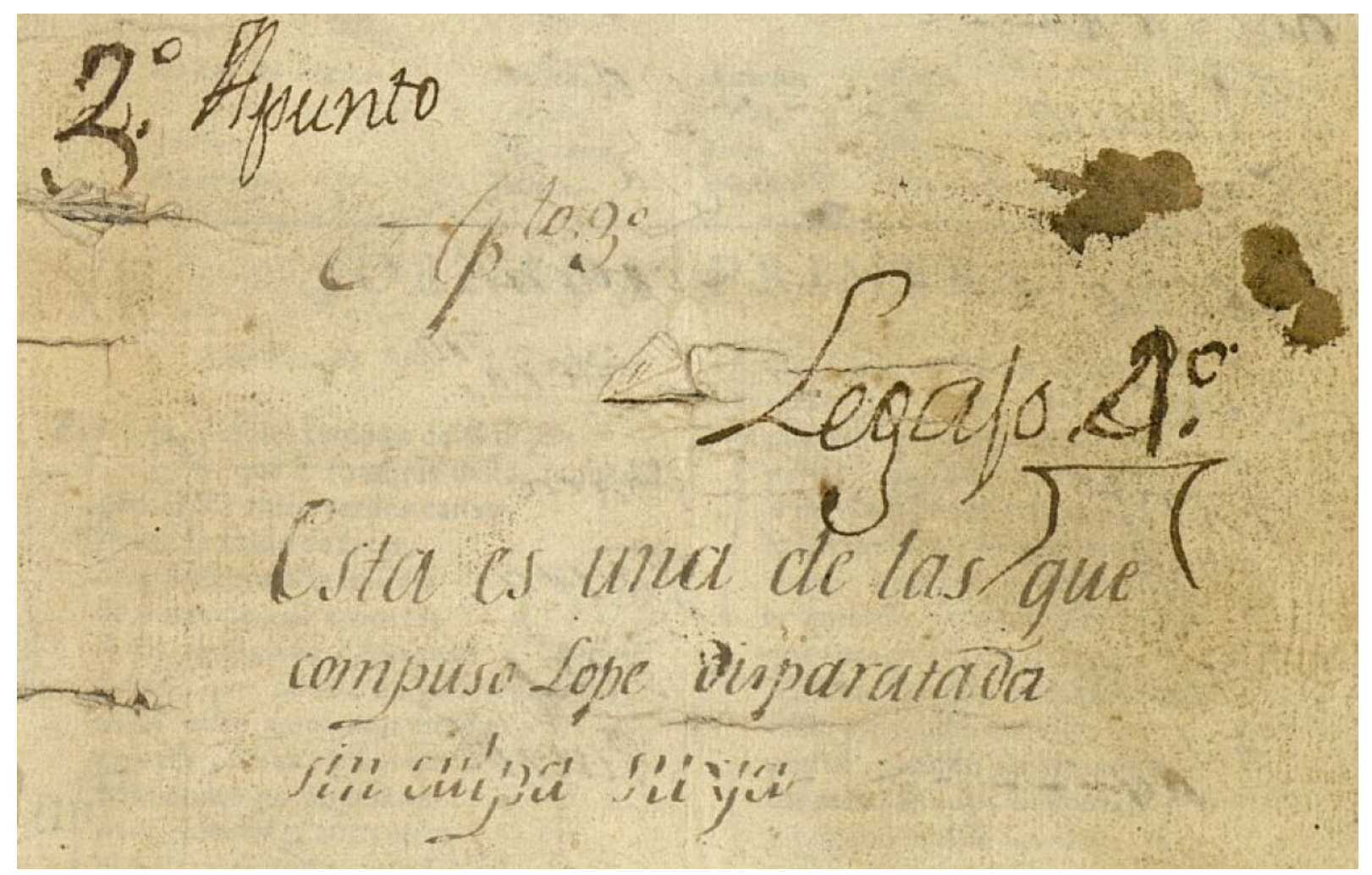

Figura 10. Portada del apunte de teatro impreso Tea-1-46-6, b minus (Biblioteca Histórica Municipal de Madrid). 


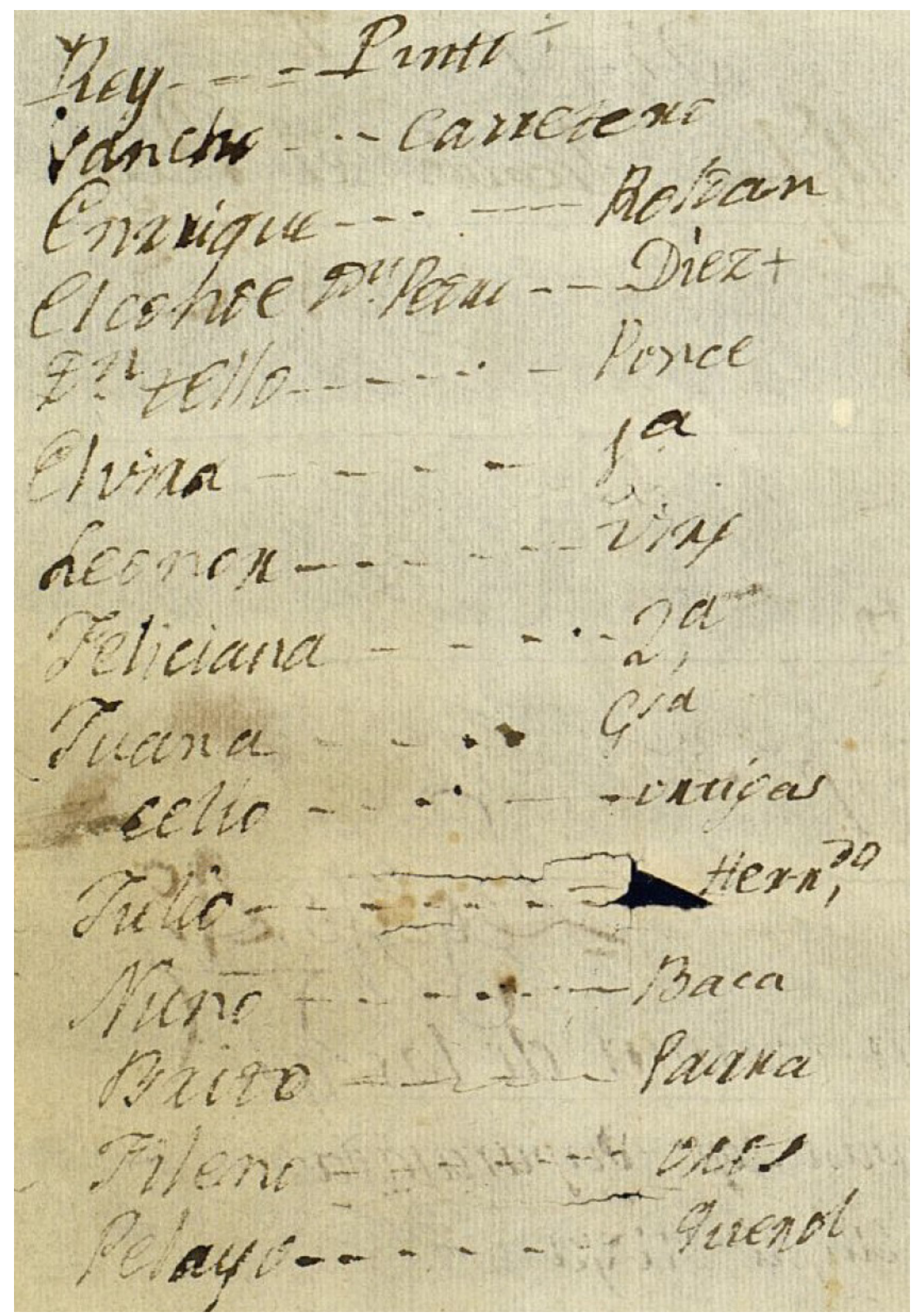

Figura 11. Vuelto de la portada del apunte de teatro impreso Tea-1-46-6, b minus (Biblioteca Histórica Municipal de Madrid). 


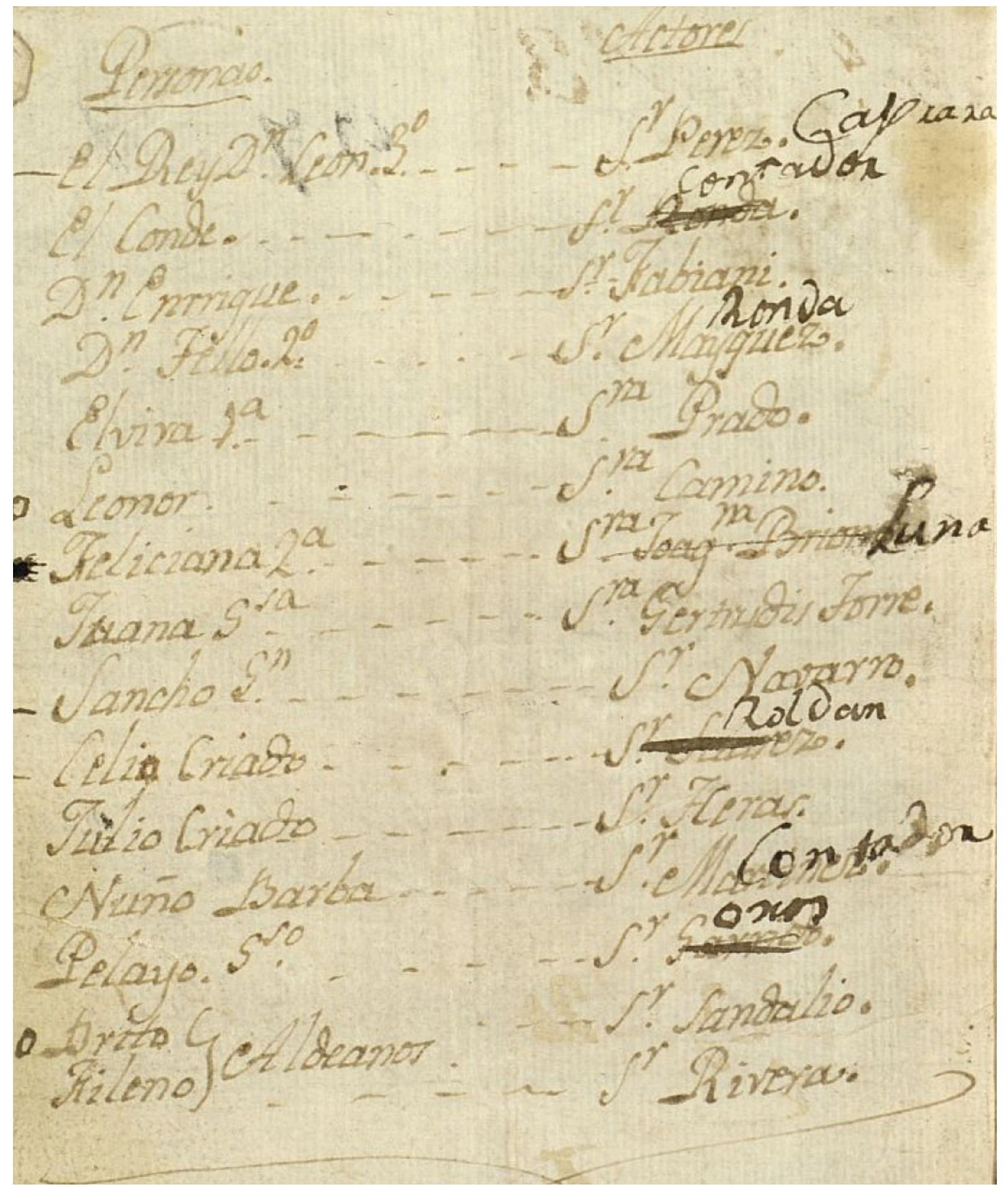

Figura 12. Vuelto de la portada del apunte de teatro impreso Tea 1-46-a2 (Biblioteca Histórica Municipal de Madrid). 


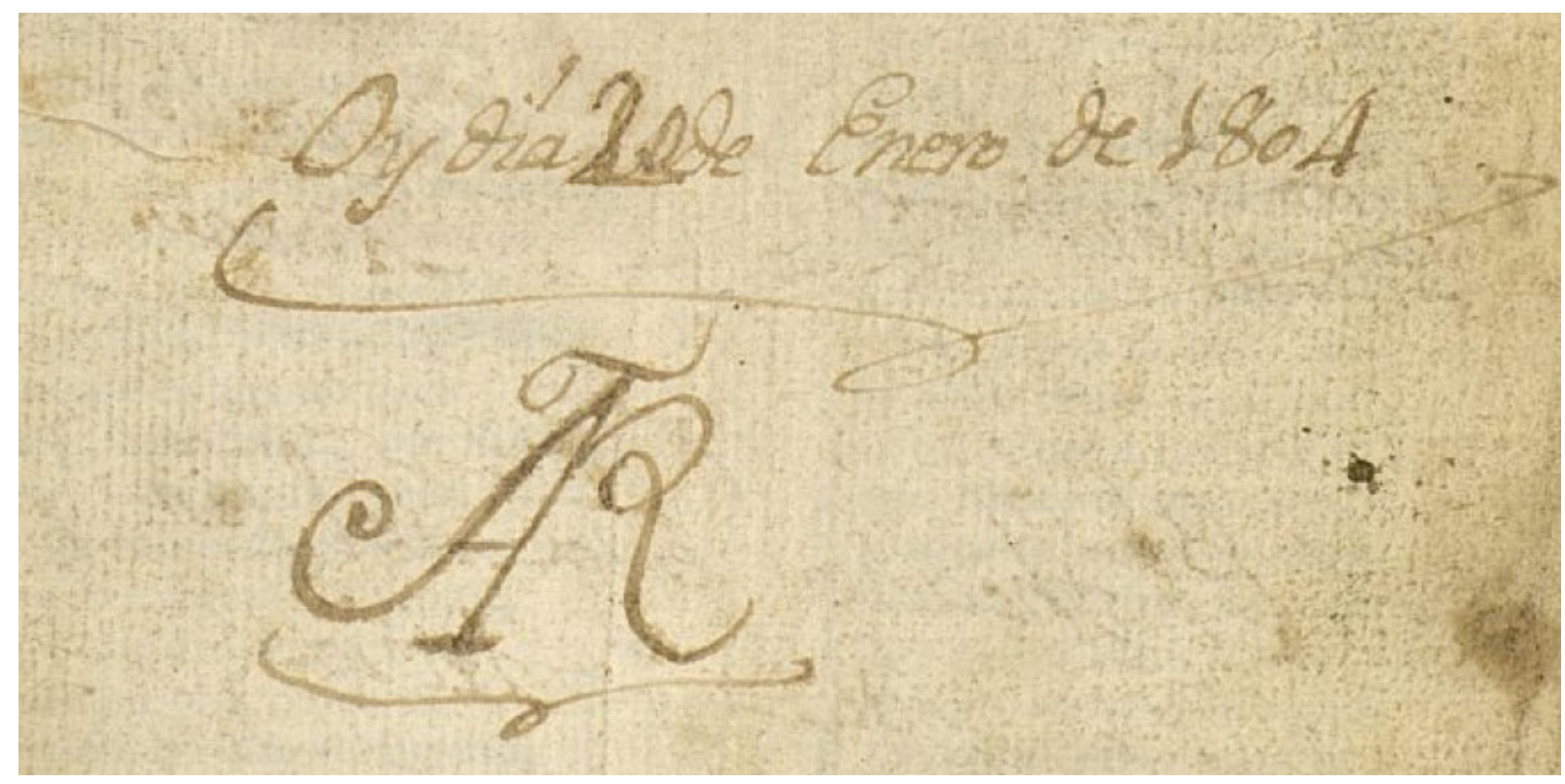

Figura 13. Detalle de la portada del apunte de teatro impreso Tea 1-46-a2 (Biblioteca Histórica Municipal de Madrid), con fecha e iniciales del apuntador. 


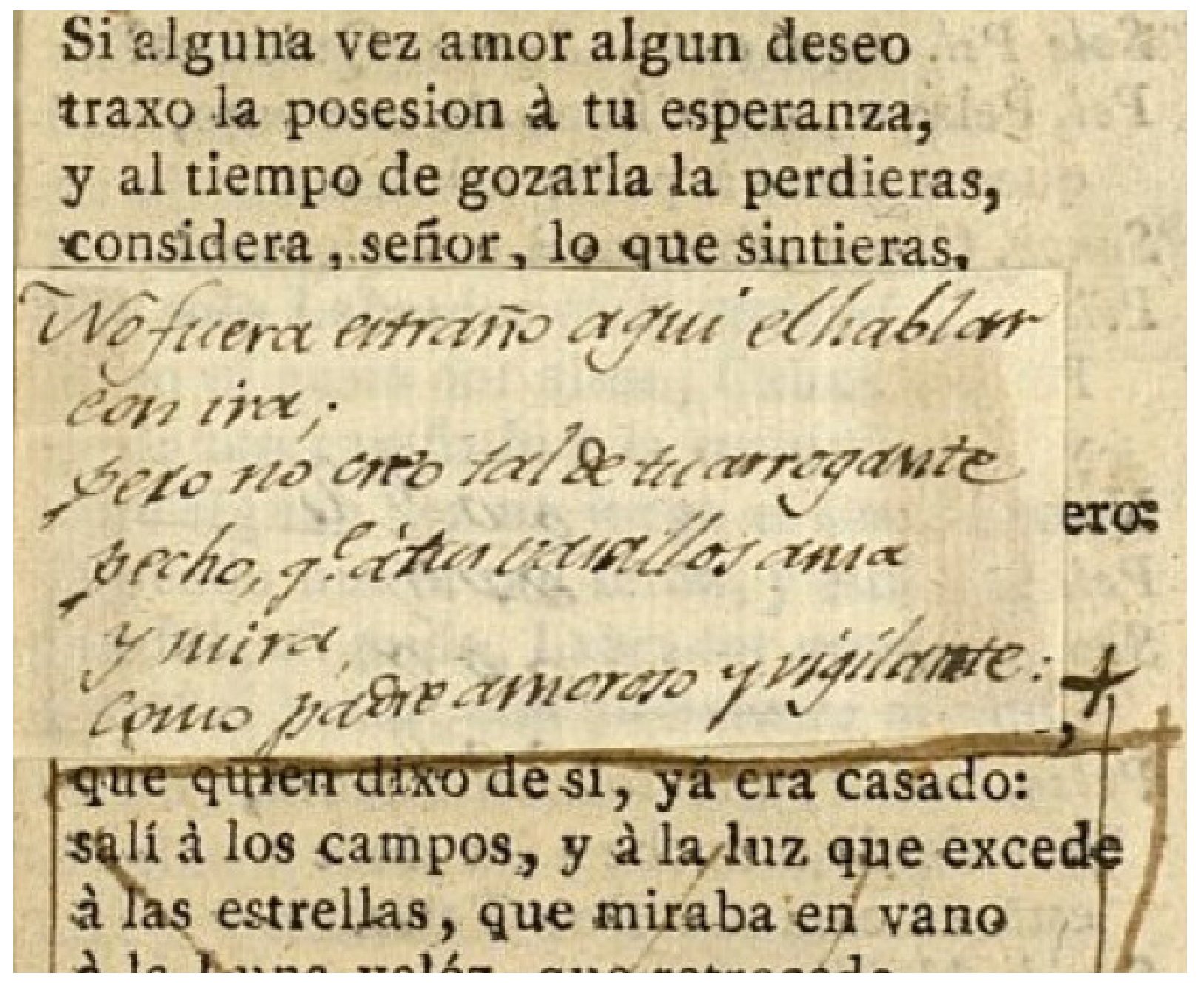

Figura 14. Banderilla en la p. 13 del apunte de teatro impreso Tea 1-46-a2 (Biblioteca Histórica Municipal de Madrid). 